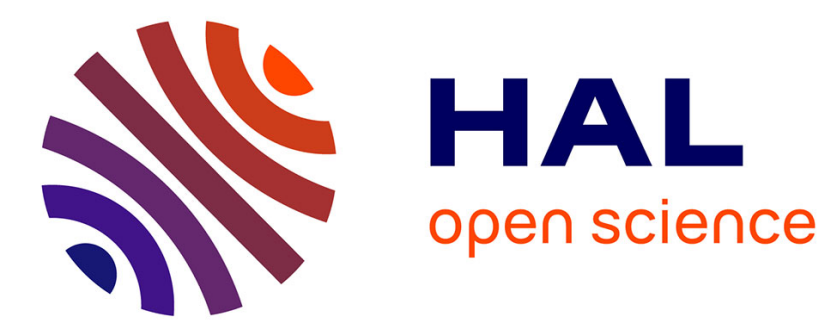

\title{
Elaboration of Polypropylene/Carbon nanotubes by Twin-screw Mixer and identification of rheological behavior
}

\author{
Hamza Djoudi, Jean-Claude Gelin, Thierry Barriere
}

\section{To cite this version:}

Hamza Djoudi, Jean-Claude Gelin, Thierry Barriere. Elaboration of Polypropylene/Carbon nanotubes by Twin-screw Mixer and identification of rheological behavior. International Journal of Advanced Manufacturing Technology, 2016, 83 (9-12), pp.1659 - 1670. hal-02946379

\section{HAL Id: hal-02946379 \\ https://hal.science/hal-02946379}

Submitted on 23 Sep 2020

HAL is a multi-disciplinary open access archive for the deposit and dissemination of scientific research documents, whether they are published or not. The documents may come from teaching and research institutions in France or abroad, or from public or private research centers.
L'archive ouverte pluridisciplinaire HAL, est destinée au dépôt et à la diffusion de documents scientifiques de niveau recherche, publiés ou non, émanant des établissements d'enseignement et de recherche français ou étrangers, des laboratoires publics ou privés. 


\section{International Journal of Advanced Manufacturing Technology Elaboration of Polypropylene/Carbon nanotubes by Twin-screw Mixer and identification of rheological behavior --Manuscript Draft--}

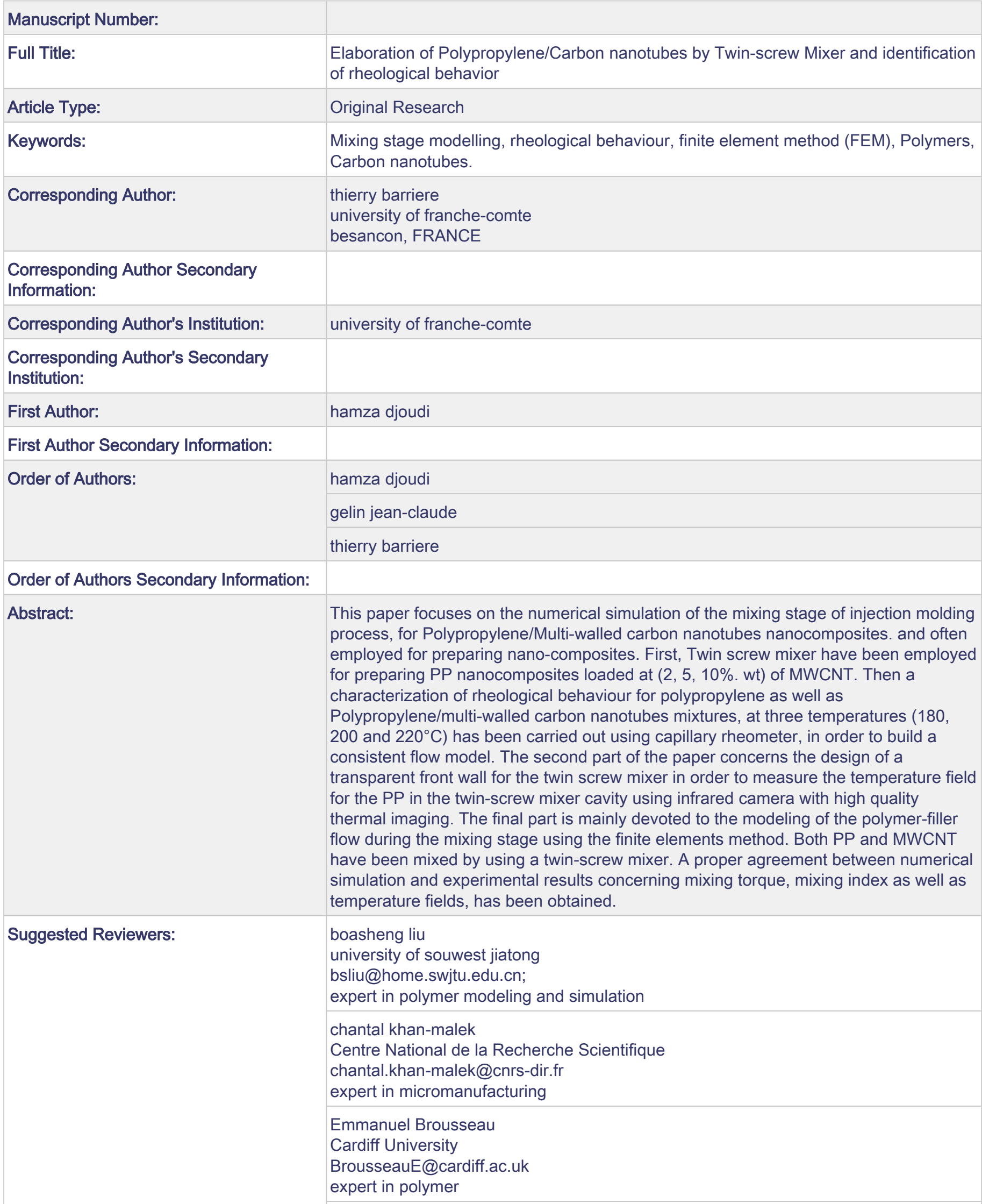


patrick rozycki

Ecole centrale de Nantes

patrick.rozycki@ec-nantes.fr

expert in modeling and simulation

danuta szeliga

univisersity of $\mathrm{AGH}$

szeliga@agh.edu.pl

expert in material characterisation

Powered by Editorial Manager ${ }^{\circledR}$ and ProduXion Manager ${ }^{\circledR}$ from Aries Systems Corporation 


\section{COVER LETTER FOR SUBMISSION OF NEW MANUSCRIPTS}

Pr T. Barriere

Tel: +33 381666075

Fax : +3338166 6700

E-mail: thierry.barriere@univ-fcomte.fr

Subject: SUBMISSION OF NEW MANUSCRIPT FOR EVALUATION

I am enclosing herewith a manuscript entitled "Elaboration of Polypropylene/Carbon nanotubes by Twin-screw Mixer and identification of rheological behavior" submitted to "Int J Adv Manuf Technol” for reviewing.

With the submission of this manuscript, I would like to undertake that the above mentioned manuscript has not been published elsewhere, accepted for publication elsewhere or under editorial review for publication elsewhere; and that my Institute's FEMTO-ST representative is fully aware of this submission.

\section{Highlights}

- Elaboration of PP/MWCNT feedstock for nanocomposite with low loading of MWCNT,

- Visualization of the temperature evolution in the twin-screw mixer by IR camera,

- Identification of behavior law Carreau-Yasuda model by experimental capillary test data,

- Modeling and 2D numerical simulation of mixing stage by Comsol multiphysics software,

- Characterization of dispersive mixing by mixing index indicator,

- Comparison between the mixing torque obtained by simulation and experiments.

Thank you for your care on the submitted work.

Sincerely yours.

Pr T. Barriere 


\title{
Elaboration of Polypropylene/Carbon nanotubes by Twin-screw Mixer and identi- fication of rheological behavior
}

\author{
H. Djoudi, J-C. Gelin, and T. Barrière \\ FEMTO-ST Institute, Applied Mechanic Laboratory, \\ 24 Chemin de l'épitaphe, \\ Besançon, 25000, \\ France. \\ Tel : +33381666010 \\ +33381666035 \\ +33381666075 \\ Fax : +33381666700 \\ hamza.djoudi@femto-st.fr \\ jean-claude.gelin@univ-fcomte.fr \\ thierry.barriere@univ-fcomte.fr
}

\begin{abstract}
This paper focuses on the numerical simulation of the mixing stage of injection molding process, for Polypropylene/Multi-walled carbon nanotubes nanocomposites. and often employed for preparing nanocomposites. First, Twin screw mixer have been employed for preparing PP nanocomposites loaded at ( 2 , $5,10 \%$. wt) of MWCNT. Then a characterization of rheological behaviour for polypropylene as well as Polypropylene/multi-walled carbon nanotubes mixtures, at three temperatures $\left(180,200\right.$ and $\left.220^{\circ} \mathrm{C}\right)$ has been carried out using capillary rheometer, in order to build a consistent flow model. The second part of the paper concerns the design of a transparent front wall for the twin screw mixer in order to measure the temperature field for the PP in the twin-screw mixer cavity using infrared camera with high quality thermal imaging. The final part is mainly devoted to the modeling of the polymer-filler flow during the mixing stage using the finite elements method. Both PP and MWCNT have been mixed by using a twin-screw mixer. A proper agreement between numerical simulation and experimental results concerning mixing torque, mixing index as well as temperature fields, has been obtained.
\end{abstract}

Keywords: Mixing stage modelling, rheological behaviour, finite element method (FEM), Polymers, Carbon nanotubes.

\section{Introduction}

Injection molding becomes a reliable manufacturing technology for complex shaped components by injecting material into a mold. Injection molding can be performed with a host of materials, including metals, glasses, elastomers, confections, and most commonly thermoplastic and thermosetting polymers. Material for the part is fed into a heated barrel, mixed, and forced into a mold cavity where it cools and hardens to the configuration of the cavity.

For a nanocomposite elaboration, mixing is the first step in the injection molding process, it is important to ensure mixture homogeneity [1] in order to avoid defects, even though mixing is very important step in the IM manufacturing process, it is probably the least understood and studied. The aim of this research is to develop engineering data needed to elaborate homogeneous mixtures. 
In this present study, an investigation about polymers and loaded polymers flow in a twin screw mixer has been carried out through numerical simulation based on the finite element method.

The first part of this paper concerns the rheological behaviour for Polypropylene "PP", as well as PP/MWCNT nanocomposite using the capillary rheometer at three temperatures $\left(180,200\right.$, and $\left.220^{\circ} \mathrm{C}\right)$, which aims to characterize theirs physical properties. The physical properties are used to identify viscosity laws parameters (Power law, Cross law, Carreau law and Carreau-Yasuda law) using Matlab ${ }^{\circledR}$ software. It is well-known that the viscosity of a polymer melt or a polymer solution changes significantly with the shear rate Fig. 2. Therefore the Newtonian model, characterized by a constant viscosity behaviour laws, is not a reasonable choice for modeling the polymeric flow. The simplest way to overcome that difficulty is to use non-Newtonian flow, i.e. to modify the Newton's model by using the variable viscosity that depends on the share-rate and temperature according to some empirical law [2]. In this paper, in order to describe the polymer flow, the shear dependent viscosities obeying the Carreau-Yasuda law has been used and gives a proper agreement with the experimental data.

The second part concerns the finite element analysis of the loaded polymer flows during the mixing process. Several 3D softwares have been developed and specially devoted to injection molding simulations such as Moldflow ${ }^{\circledR}$, Sigma3D $^{\circledR}$, Cadmould $^{\circledR}$. They are well suited to help design of molds and parts, but show limits when considering micro-geometries. Indeed, some research group developed their home made FEM 3D software to properly consider specific boundary conditions. Comsol ${ }^{\circledR}$ software has been chosen in this study because of its efficiency for solving multiphysic coupled problems as well as the possibility to add PDE (Partial Differential equations) and it can be connected to Matlab ${ }^{\circledR}$. This approach allows to determine velocity fields and to relate shear rates, as well as temperature fields during the mixing stage. An excellent agreement between the experimental measured torque on the screw and the calculated one has been obtained. Therefore, one can consider that the physical flow is properly. well described.

\section{Elaboration of the mixtures for rheological testing and characterization}

Several feedstocks have been produced with a co-rotating twin screw mixer "Brabender ${ }^{\circledR}$ (Plastograph EC W50EHT, Fig. 1)" this is equipment can be configurated with different blades (roller, sigma, delta...). Within a series, the free mixer volume varies depending on the blades mounted, as example the use of roller blades allows to elaborate feedstocks up to $40 \mathrm{~cm}^{3}$. The temperature in the mixing cavities is regulated and can reach $500^{\circ} \mathrm{C}$. Counter-rotation towards each other at different speeds provides excellent compounding and mixing characteristics, the speed ratio driven at idle screw is about 2:3. The fluid is contained in the cavity enclosed by the frame and the two screws. The left screw rotates in the clockwise while the right one rotates in the counter clockwise, the advantages of counter-rotating twin screw mixers are such as: forced feed, high output at short residence time, self-cleaning and careful plastification. Both mixing torque and temperature are measured using sensors and software. At first the polypropylene PP has been mixed at fixed temperature $200^{\circ} \mathrm{C}$, and a screw speed eq. $60 \mathrm{rpm}$. After that PP has been mixed with various multi wall carbon nanotubes (MWNTs) content (2, 5 and $10 \%)$. The mixing temperature is fixed to $200^{\circ} \mathrm{C}$ [3], with a screw speed fixed to $60 \mathrm{rpm}$. The specifications of MWNTs are as follows according to the specifications of the provider: diameter 9-11 nm range, mean length of the nanotubes: $1.2 \mu \mathrm{m}$, density $1.3 \mathrm{~g} / \mathrm{cm}^{3}$, and purity higher than $90 \%$. 
In order to build a consistent and appropriate viscosity model, a rheological characterization has been performed. The shear viscosities of PP and PP/MWCNT have been evaluated at different temperatures. The viscosity melt shows shear thinning non-Newtonian behaviour as shown in Figure 2-3. RH2000 capillary rheometer (Die diameter $(\phi=1 \mathrm{~mm})$ ) is used for these measurements in the shear rate range $\left(10-10^{4}\right.$ $\mathrm{s}^{-1}$ ). The shear viscosity vs the shear rate for PP and PP/MWCNT, are related in Fig. 2. The test temperature influence on the shear viscosity is shown in the Fig. 3 for the $10 \mathrm{wt}$ \% PP/MWCNT composite. One can notice that the same results pattern is identifiable to the other temperatures and the other composites. One can notice that the same pattern results could be identifiable to the other temperatures and the other feedstocks (Pure PP and 2, 5 and 10 wt.\% PP/MWCNT nanocomposites). This fixed value of the shear rate corresponds to an average shear rate of the mixing phase. At fixed temperature, the shear viscosity of the pure PP and PP/ MWCNT feedstocks decreases with the increase of the shear rate. These viscosity curves clearly indicate the significant effect of the MWCNTs content. When the shear rate is in the range $\left(10-10^{2}\right.$ $\mathrm{s}^{-1}$ ), the PP/MWCNT feedstocks exhibit a shear thinning effect whereas the pure PP exhibits only small shear rate dependence, revealing a Newtonian plateau. However, from $220^{\circ} \mathrm{C}$, the PP viscosity curves present a much steeper slope at low shear rate, that means no Newtonian plateau within the shear rate range studied. On the other hand, when the shear rate is in the range $\left(10^{2}-10^{4} \mathrm{~s}^{-1}\right)$ it is interesting to remark that with a 2, 5 and $10 \%$ loading of MWCNT, the flow characteristics of the nanocomposite is practically the same as the pure polypropylene. This is an interesting aspect because it means that this new material will be a "drop-in" additive which will result in greater physical properties in the end product. Both PP and its nanocomposites showed non-Newtonian behavior. When the shear rate is increasing, the shear thinning effect is enhanced and the wall slip phenomena occurring between PP/MWCNT as well as the wall of the rheometer is predominant, as it is supposed [4] and [5]. Finally for one PP/MWCNT composite shade, the viscosity curves indicate a decrease of the shear viscosity with the increase of the temperature Fig. 3. This is related to the fact that the shear viscosity of the polypropylene decreases when heating. At low shear rates, the addition of MWNT content causes an increase in viscosity; however, viscosity is less sensitive to addition of MWNT content at higher shear rates. 


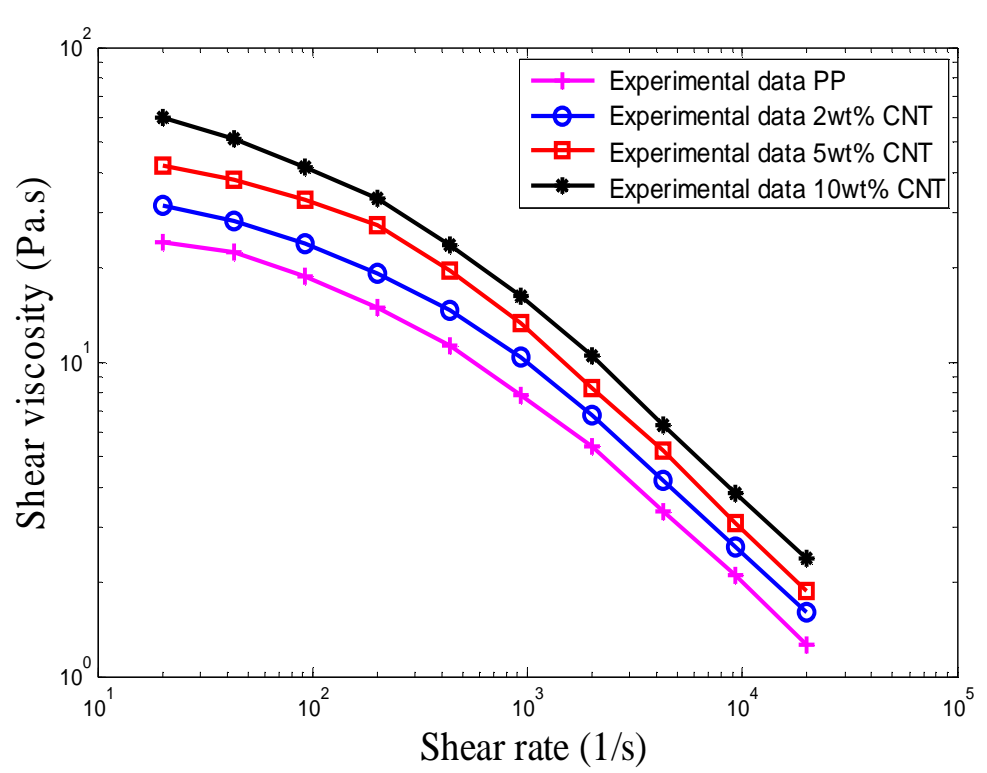

Fig. 2: Shear viscosity vs the shear rate measured at $200^{\circ} \mathrm{C}$ for the $\mathrm{PP}$ and $\mathrm{PP} / \mathrm{MWCNT}$

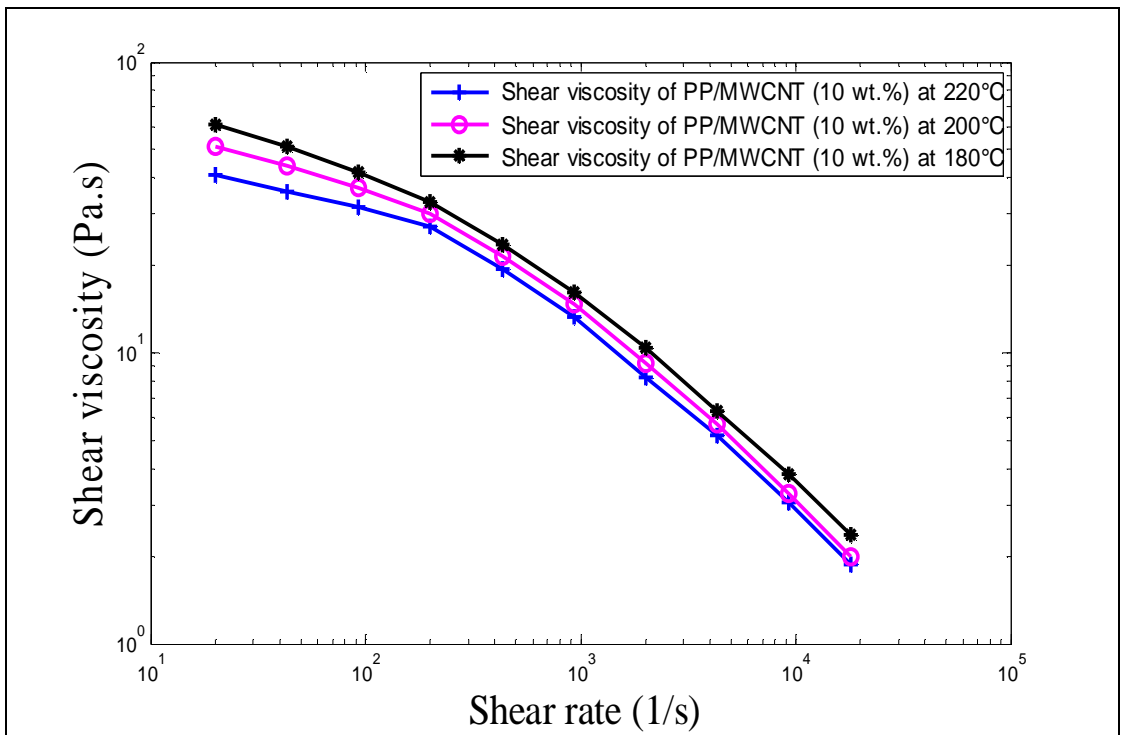

Fig. 3: Shear viscosity vs shear rate measured at 180,200 and $220^{\circ} \mathrm{C}$ for the $10 \% \mathrm{PP} / \mathrm{MWCNT}$ feedstock

There are many equations which relate viscosity as a function of shear rate: power-law, Cross, and Carreau-Yasuda are the most common appearing in literature [3, 6]. Particularly the power-law model, is perhaps the most widely applied in many fields, which can be a result of its proper form of equations providing reasonable fitting, and also, a reasonable representation of equation constants in terms of degree of viscous and fluid flow behaviour. These equations are now expressed and described:

$$
\begin{gathered}
\mu(T, \dot{\gamma})=\mu_{0}(T) \dot{\gamma}^{n} \\
\mu(T, \dot{\gamma})=\frac{\mu_{0}(T)}{(1+\lambda \dot{\gamma})^{1-n}} \\
\mu(T, \dot{\gamma})=\mu_{0}(T)\left(1+(\lambda \dot{\gamma})^{a}\right)^{\frac{n-1}{a}}
\end{gathered}
$$


where $\mu_{0}$ is the shear viscosities at zero shear-rate; $T$ is the temperature; $\lambda$ is a time scale; $n$ and $a$ are power indexes and $\dot{\gamma}$ is the shear rate expressed as followed in a Cartesian coordinate system:

$$
\dot{\gamma}=(1 / 2 D: D)^{1 / 2}
$$

where $\overline{\bar{D}}$ is the strain rate tensor. Apart from the effect of shear rate, viscosity is also highly influenced by the changes of fluid body temperature. Fluid viscosity as a function of temperature normally exhibits a correlation between natural logarithmic of the viscosity and the reciprocal of absolute temperature. Thus, its relation is well represented by Arrhenius-type relationship [6], which has the following form of equation:

$$
\mu_{0}(T)=\mu_{0} e^{-b T}
$$

The power law (1) is useful because of its simplicity, but this law only describes approximately the behaviour of a real non-Newtonian fluid. For example, if $n$ were less than one, the power law shows that the effective viscosity would decrease with increasing shear rate indefinitely, requiring a fluid with infinite viscosity at rest and zero viscosity as the shear rate approaches infinity, but a real fluid has both a minimum and a maximum effective viscosity that depend on physico-chemical properties at the molecular level. Therefore, the power law is only a phenomenological description of fluid behaviour across the range of shear rates to which the coefficients were fitted. From Carreau-Yasuda law (3), we find the Cross law (2) for $\mathrm{a}=1$ and Carreau law for $\mathrm{a}=2$. The laws appear to be a well suited compromise between the number of parameters used and the correct fit of experimental curves. The effect of the parameter (a) is shown in Fig. 5. Normally, (a) is less than one. Experimentally, it is first necessary to accurately determine the values of $\mu_{0}(T)$ and $n-1$ before defining $a$. This law is mostly used for many polymers, as well as loaded polymers.

The rheological parameters $\mu_{0}, \lambda, a, b$ and $n$ were identified for each empirical model by solving an inverse problem using Matlab ${ }^{\circledR}$ software in order to reduce the discrepancy between experimental and models "Fig. 4". The inverse problem is formulated as finding a set of rheological parameters starting from an analytical form of the constitutive equation to be identified through minimization of a coast fucntion [7]. The goal is to compute the parameter vector which minimizes an objective function representing, in the least square sense, the difference between experimental and numerical data.

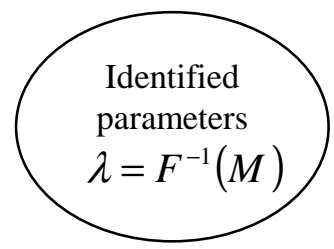

Inverse problem

Fig. 4: Inverse problem scheme
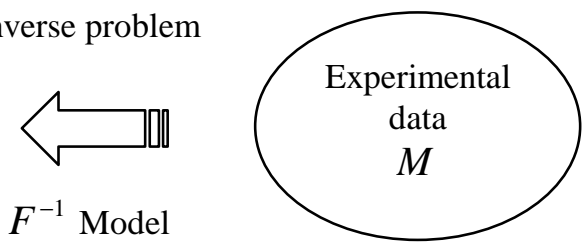

In order to compare the trends of the various models, the evolution for PP/MWCNT $10 \mathrm{wt} . \%$ is represented in Fig. 5. The model parameters have been listed in the following Table 1.

Table 1: Rheological models parameters for the PP/MWCNT $10 \mathrm{wt} . \%$

\begin{tabular}{|l|c|c|c|c|c|c|}
\hline & $T_{\text {ref }}{ }^{\circ} \mathrm{C}$ & $\mu_{0}$ & $\lambda(\mathrm{s})$ & $n$ & $a$ & $b$ \\
\hline Carreau-Y & 200 & 80 & 0.17 & 0.38 & 0.16 & 0.015 \\
\hline
\end{tabular}




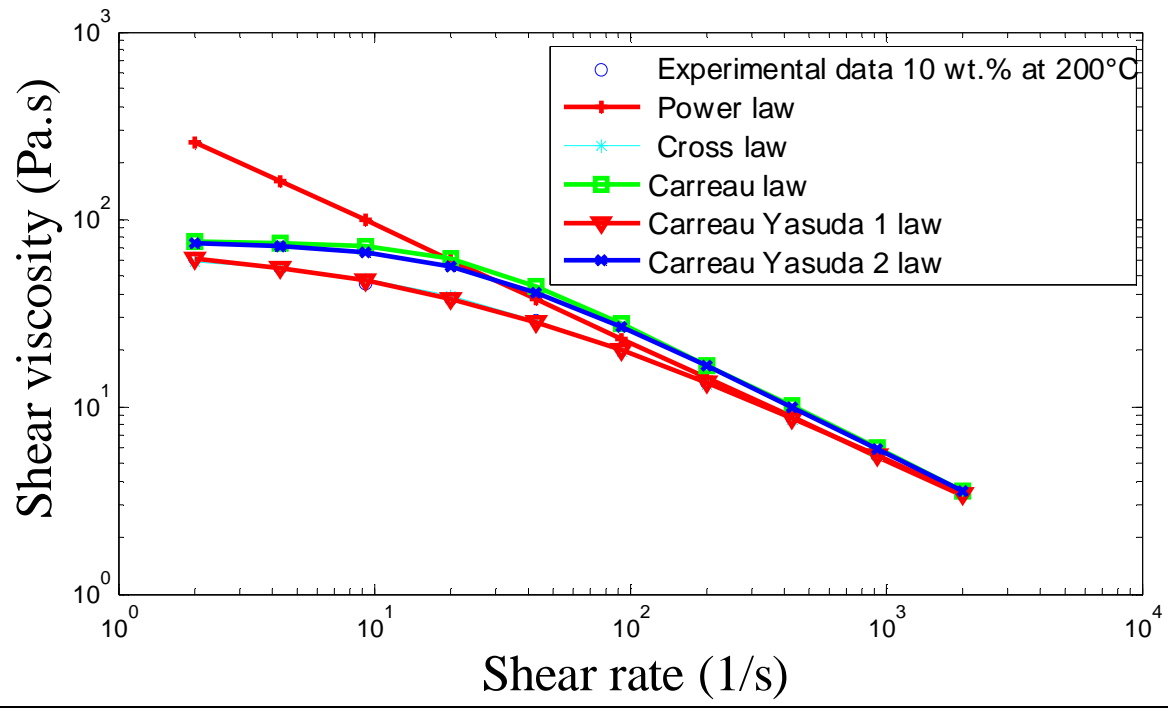

Fig. 5: Comparison of different flow models for PP/MWCNT $10 \mathrm{wt} . \%$

Comparison between the experimental data and the identified Carreau-Yasuda law for the pure PP and each PP/MWCNT composite is described in Fig. 6. One can notice a proper correlation between experimental and Carreau-Yasuda model datas [6].

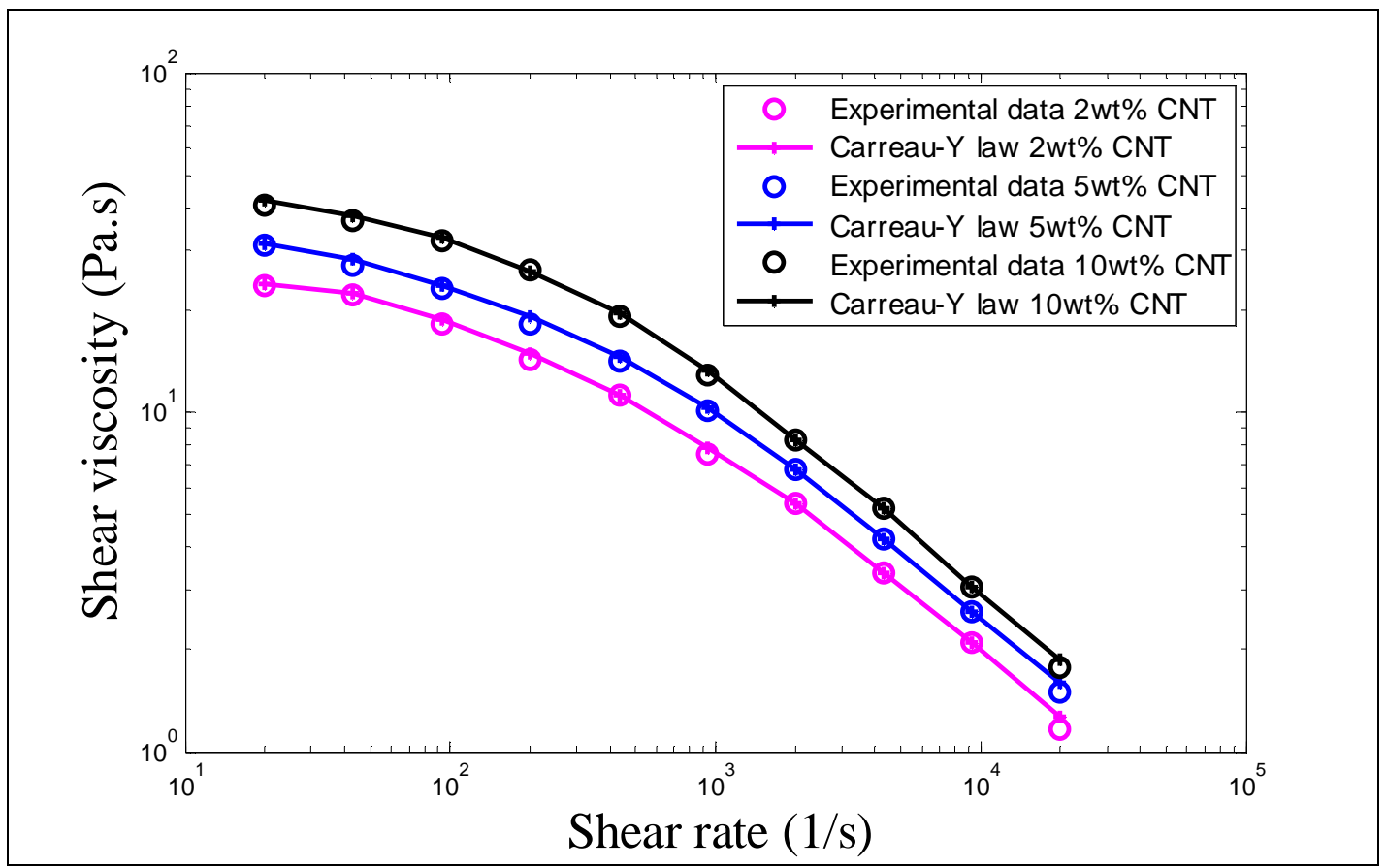

Fig. 6: Shear viscosity as a function of the shear rate measured at $200^{\circ} \mathrm{C}$ for the PP and PP/MWCNT feedstocks: experimental datas and Carreau law enriched temperature fitting curves.

\section{Numerical simulation for mixing stage}

In the present work, $\mathrm{Comsol}^{\odot}$ software has been used to simulate the loaded polymer PP/MWCNT 10 wt. \% feedstock flow in co-rotating twin-screw mixer. The geometry of twin-screw mixer used for the flow simulation is the same that Brabender ${ }^{\circledR}$ (Plastograph EC W50EHT). Fig. 1 shows the finite element mesh 
used for the flow simulation. For the flow simulation, the screws rotate at $60 \mathrm{rpm}$ to provide excellent compounding and mixing characteristics. Since the present work at this stage is not focused on predicting the quality of mixing for specific polymers and loaded polymers, for the time being, a Non-Newtonian fluid model was used in the simulation.

\subsection{Coupled Navier-Stokes Equations}

In order to perform the numerical simulation of the mixing stage of PP/MWCNT, Navier-Stokes equations are essential to describe the fluid motion and to define a suitable model of the flow into the subdomains $\Omega_{1 \cup 2 \cup 3}$ where $\Omega_{1}$ is the outer subdomain and $\Omega_{2 \cup 3}$ are the inner subdomains as shown in Fig.7.

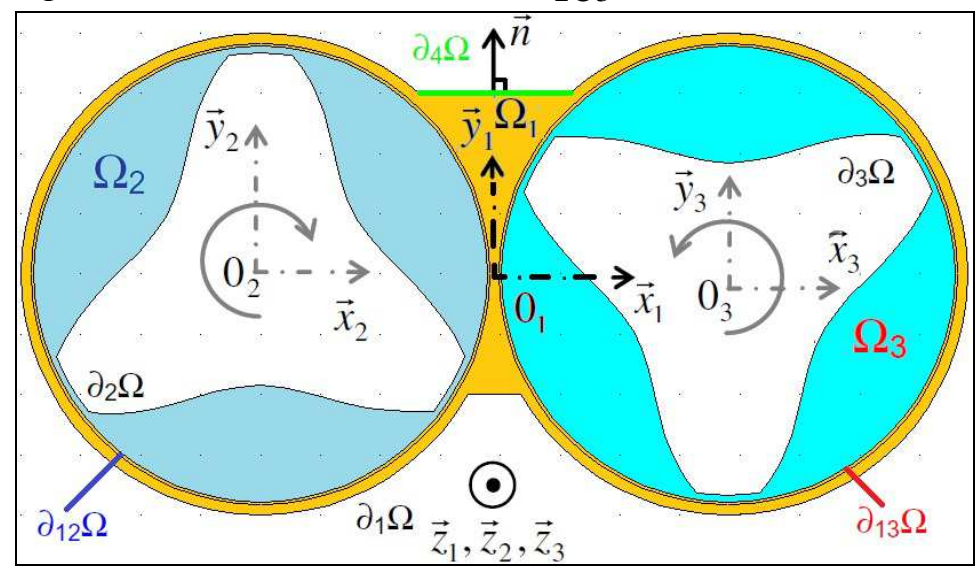

Fig. 7. Description of the geometrical problem of the twin-screw mixing chamber in term of material frames and boundary conditions definition.

$$
\begin{aligned}
\nabla \cdot u & =0 \\
\rho \frac{\partial u}{\partial t}+((u-w) \cdot \nabla) u & =-\nabla \sigma I+\mu(\dot{\gamma}, T) \Delta u+f
\end{aligned}
$$

where $I$ is the identity tensor, $\rho$ is the fluid density and $\mathrm{f}$ is the external body force per unit mass. The stress tensor $\sigma$ given in (7) incorporates the isotropic pressure $(p)$ and extra stress tensor $(K)$, defined as

$$
\sigma I=p I+K
$$

When the influence of the temperature is taken into account, the temperature is described by the following convection and diffusion equation:

$$
\rho C_{p} \frac{\partial T}{\partial t}+\rho C_{p} u . \nabla T-\nabla \cdot[k \nabla T]=K
$$

where $C_{p}$ is the heat capacity of the mixture, $k$ the thermal conductivity, and $T$ is the temperature in the mixing chamber. The extra stress tensor of (9)for a generalized Newtonian fluid in an isothermal flow is given by

$$
K=2 \mu(\dot{\gamma}, T) D
$$

where $D$ is the rate of deformation tensor and $\mu(\dot{\gamma}, T)$ is the Carreau-Yasuda viscosity function of the local shear rate, $\dot{\gamma}$ and the temperature $T$, as given in (3).

\subsection{Dispersive mixing characterization}

Studies of droplet breakup in simple shear and pure elongational flows have shown that elongational flows are more effective, especially in the case of polymeric blends with high viscosity ratios and low interfacial tension. The magnitude of the applied stresses can also affect the morphology of the resulting blend. Manas-Zloczower and Feke [8-9] formulate the same conclusion for the dispersion of solid ag- 
glomerates in liquids. As in work previously done, the dispersive mixing efficiency of a flow field can be characterized in terms that account for the elongational flow contribution and the magnitude of stresses generated. One simple way to quantify the elongational flow components is to compare the relative magnitudes of the rate of deformation, $D$, and the vorticity, $\omega$, tensors. The parameter $\lambda_{M I}$, defined as:

$$
\lambda_{M I}=\frac{D}{D+\omega}
$$

can be used as a basic measure of the mixing efficiency when assessing processing and/or operating conditions. $\lambda_{M I}$ is equal to one for pure elongation, 0.5 for simple shear and zero for pure rotation. Therefore, the closer the value of $\lambda_{M I}$ is to one, the better the dispersive mixing efficiency.

\subsection{Mixing torque calculation}

In order to calculate the mixing torque, an important physical quantity which is the stress tensor must be defined. The stress state at a point on the surface of the mixing screw is defined by stress vector as:

$$
\vec{T}^{(n)}=\overline{\bar{\sigma}} \cdot \vec{n}
$$

This relationship implies that the stress vector $\vec{T}^{(n)}$ at any point $\mathrm{P}$ in a continuum associated to a surface with local normal unit vector $\vec{n}$ can be expressed as a function of the stress vectors associated to the coordinate axes planes, i.e. in terms of the components $\sigma_{i j}$ of the stress tensor:

$$
\overline{\bar{\sigma}}=\left[\begin{array}{l}
T^{(e 1)} \\
T^{(e 2)} \\
T^{(e 3)}
\end{array}\right]=\left[\begin{array}{lll}
\sigma_{11} & \sigma_{12} & \sigma_{13} \\
\sigma_{21} & \sigma_{22} & \sigma_{23} \\
\sigma_{31} & \sigma_{32} & \sigma_{33}
\end{array}\right]=\left[\begin{array}{ccc}
\sigma_{x} & \tau_{x y} & \tau_{x z} \\
\tau_{y x} & \sigma_{y} & \tau_{y z} \\
\tau_{z x} & \tau_{z y} & \sigma_{z}
\end{array}\right]
$$

where $\sigma_{11}, \sigma_{22}$, and $\sigma_{33}$ are normal stresses, and $\sigma_{12}, \sigma_{13}, \sigma_{21}, \sigma_{23}, \sigma_{31}$, and $\sigma_{32}$ are shear stresses. Thus the stress tensor for a non-Newtonian fluid is written in Cartesian coordinate [10] as:

$$
\begin{gathered}
\sigma_{11}=\sigma_{x}=-p+2 \mu u_{x} \\
\sigma_{22}=\sigma_{y}=-p+2 \mu v_{y} \\
\sigma_{33}=\sigma_{z}=-p+2 \mu w_{z} \\
\sigma_{12}=\tau_{x y}=\tau_{y x}=\mu\left(u_{y}+v_{x}\right) \\
\sigma_{23}=\tau_{y z}=\tau_{z y}=\mu\left(v_{z}+w_{y}\right) \\
\sigma_{13}=\tau_{x z}=\tau_{z x}=\mu\left(u_{z}+w_{x}\right)
\end{gathered}
$$

where $(u, v, w)$ are the velocity components in the Cartesian coordinate, and $u_{x}=\frac{\partial u}{\partial x}, u_{y}=\frac{\partial u}{\partial y}$, $u_{z}=\frac{\partial u}{\partial z}=0, v_{x}=\frac{\partial v}{\partial x}, v_{y}=\frac{\partial v}{\partial y}, v_{z}=\frac{\partial v}{\partial z}=0, w_{x}=\frac{\partial w}{\partial x}, w_{y}=\frac{\partial w}{\partial y}, w_{z}=\frac{\partial w}{\partial z}=0$, and $\mu(\dot{\gamma}, T)$ is the viscosity "Eq. (3)"

Generally the mechanic torque is defined as

$$
\overrightarrow{T q}=\vec{F} \otimes \vec{r}
$$

where $\overrightarrow{T q}$ is the torque vector and $T q$ is the magnitude of the torque, $\vec{r}$ is the displacement vector. vector from the point from where the mechanical torque is measured to the point where force is applied), $\vec{F}$ is the 
load vector, and $F$ is the magnitude of the load, in case of the mixing screw, $\vec{r}$ represents the displacement vector from the center of the screw cross section to a point belonging to the screw side surface, and $\vec{F}$ is the product of normal stress acting on the side area of the screw "A", and the side area itself. Thus the mixing torque is expressed as:

$$
\overrightarrow{T q}=\int_{A} \vec{r} \otimes \vec{T}^{(n)} \cdot d A=L \int_{l} \vec{r} \otimes \vec{T}^{(n)} \cdot d l
$$

where $\vec{r}$ represents the displacement vector from the center of the screw cross section to a point belonging to the screw side surface "A" and $L$ is the screw length in the $\mathrm{z}$ direction and is eq. $48 \mathrm{~mm}$. The integration is easily performed on the screw side area using $\mathrm{Comsol}^{\circledR}$, the mixing torque is than calculated at each time step for the PP/MWCNTs nanocomposites as shown in Fig. 15.

\subsection{Material and process numerical implementation}

The $\mathrm{Comsol}^{\odot}$ Multiphysics engineering simulation software environment facilitates all steps in the modelling process defining the geometry, meshing, specifying the physics, solving, and then visualizing of results. The fluid-thermal model has been implemented and can be assimilated to a multiphysic coupled problem between the "fluid flow module" (for the fluid problem), "heat transfer module" (for the thermal problem) and the "ALE moving mesh module" (for the moving meshes) as shown in Fig. 9. The total number of triangular elements is 3846 with 2373 nodes for the 2D model see Fig. 8. The rotation speed is fixed to $60 \mathrm{rpm}$ for the idle screw, with maximum mixing temperature up to $200^{\circ} \mathrm{C}$ for the all feedstocks. An explicit time stepping scheme is used for the time dependant solver algorithm. The solution is given on the actual frames at each time step until final time $t f=6 \mathrm{~s}$ ( 6 revolutions). The computer characteristics are CPU : Intel ${ }^{\circledR}$ Pentium ${ }^{\circledR}$ Dual $2.40 \mathrm{GHz}$ and RAM: 6.00Go.

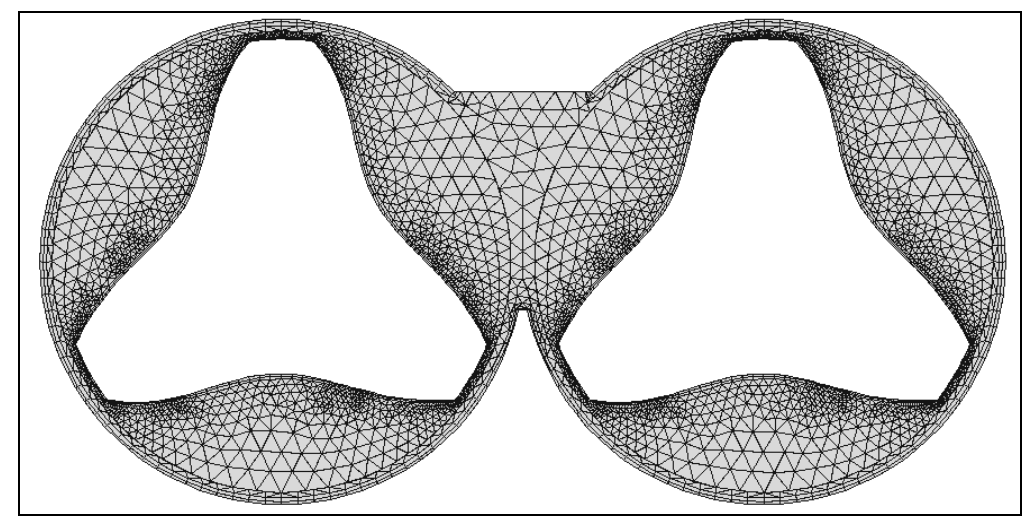

Fig. 8: Mesh definition related to twin screws mixer discretization (30876 DOF) 


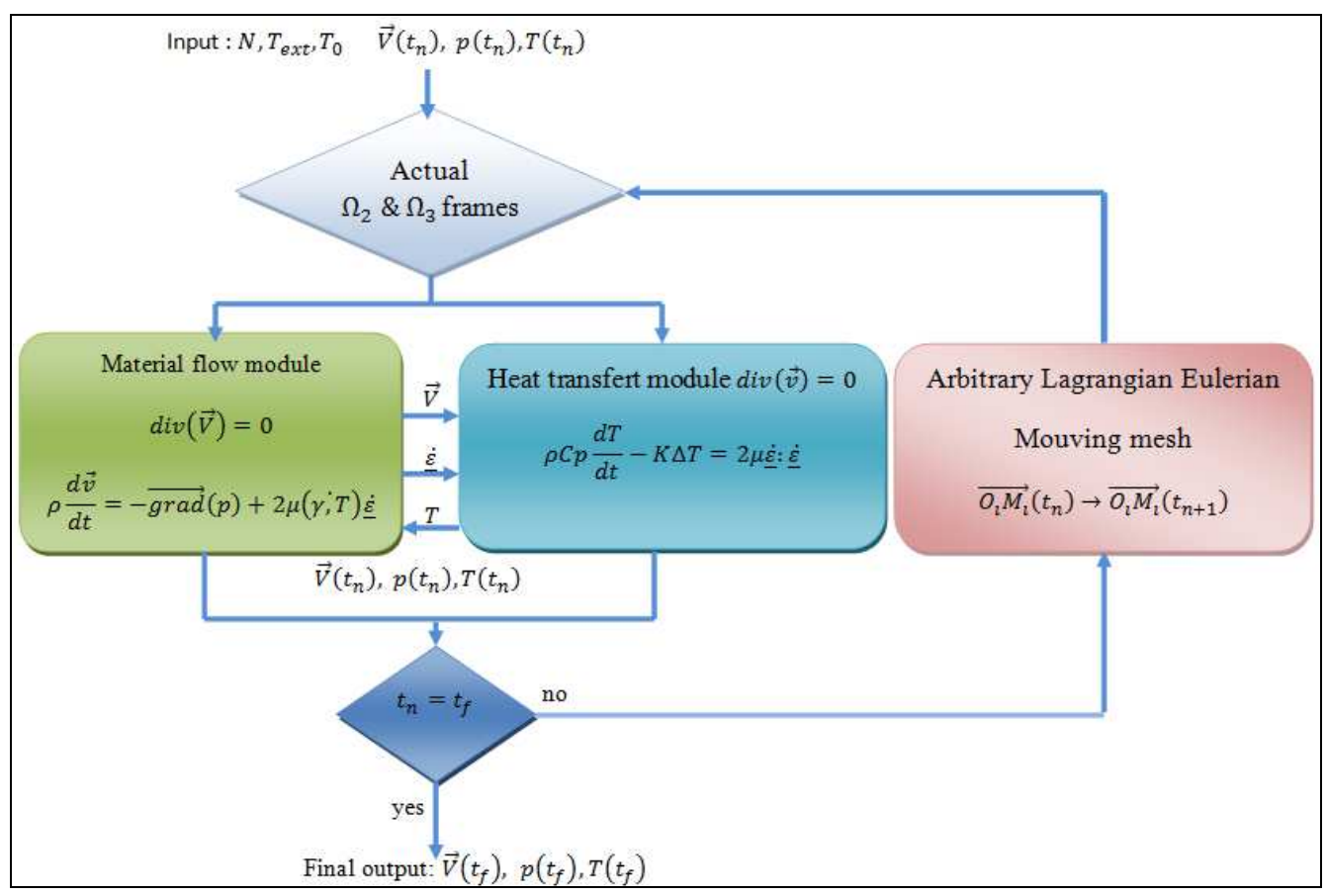

Fig. 9: Interactions algorithm between "material flow", "heat transfer" and "moving mesh module".

Table 2: Physical and thermal parameters for the PP and PP/MWCNT 10 wt.\% Feedstock.

\begin{tabular}{|c|c|c|c|}
\hline & $\rho\left(\mathrm{cm}^{3} / \mathrm{g}\right)$ & $C_{p}\left(\mathrm{~J}^{\mathrm{kg}} \mathrm{g}^{-1}\right)$ & $k\left(W \mathrm{~m}^{-1} \mathrm{~kg}^{-1}\right)$ \\
\hline PP & 0.904 & 1800 & 0.2 \\
\hline PP/MWCNT & 0.816 & 2100 & 0.35 \\
\hline
\end{tabular}

\section{Results and discussion}

\subsection{Vectors velocity profiles}

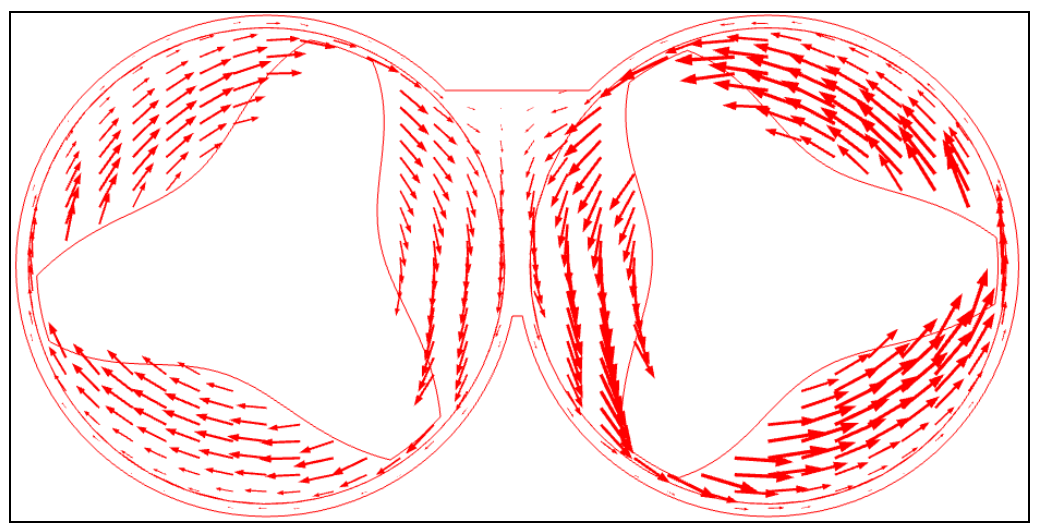

Fig. 10: Velocity vectors indicating direction of the PP/MWCNT $10 \mathrm{wt}$ \% flow and velocity magnitude $(\mathrm{m} / \mathrm{s})$ of the twin screw mixer after 3 revolutions 
The velocity vectors indicating direction at one position in the twin screw mixer are featured in Fig. 10. They have been color scaled by the velocity magnitude.

\subsection{Dispersive mixing}

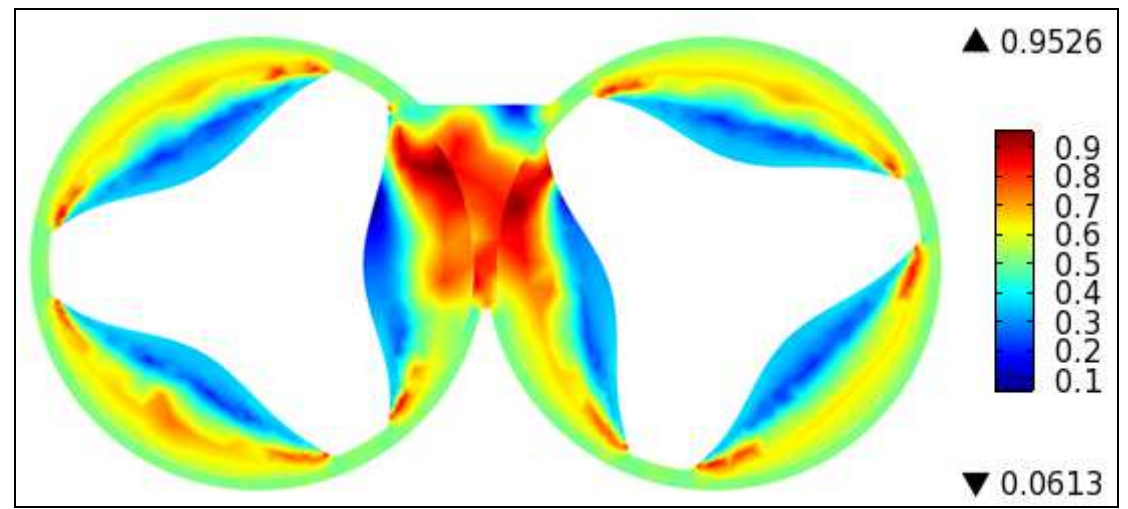

Fig. 11: Mapping of the mixing index $\left(\lambda_{M I}\right)$ for PP/MWCNT $10 \mathrm{wt} . \%$ in the twin screw mixer after 3 revolutions from the initial position (a value eq.0 indicates pure rotation, a value eq. 0.5 indicates shear flow and a value of 1 indicates pure elongation).

A mapping of the inertial reference frame mixing index results in Fig. 11 show the mixer mainly used primary a shearing mechanism. The areas with the lowest $\lambda_{M I}$ values in the zones of the twin screw mixer that are closed from the screw interaction region in Fig. 11. The rotating reference frame velocity is at a local maximum at the low point of the mixing index with a wide band of nearly constant values. The low values of the $\lambda_{M I}$ and shear stress, together with the constant rotating reference frame velocity, indicate that the fluid in this zone is moving as a plug around the center of rotation zone rotating, but not deforming. The part of the flow with the most elongational character twin-screw mixer like flow domains occurring between the center of rotation and the plug flow zone. Unfortunately, since the shear stress is relatively low throughout that zone, the mixing there will still be less effective at dispersing cohesive clumps, immiscible droplets or bubbles. The zone of predominately elongational flow like flow domains continues to coincide with relatively low shear stress until close the screw tips, where the highest shear stresses are found in the single screw mixer

\subsection{Shear rate profiles}

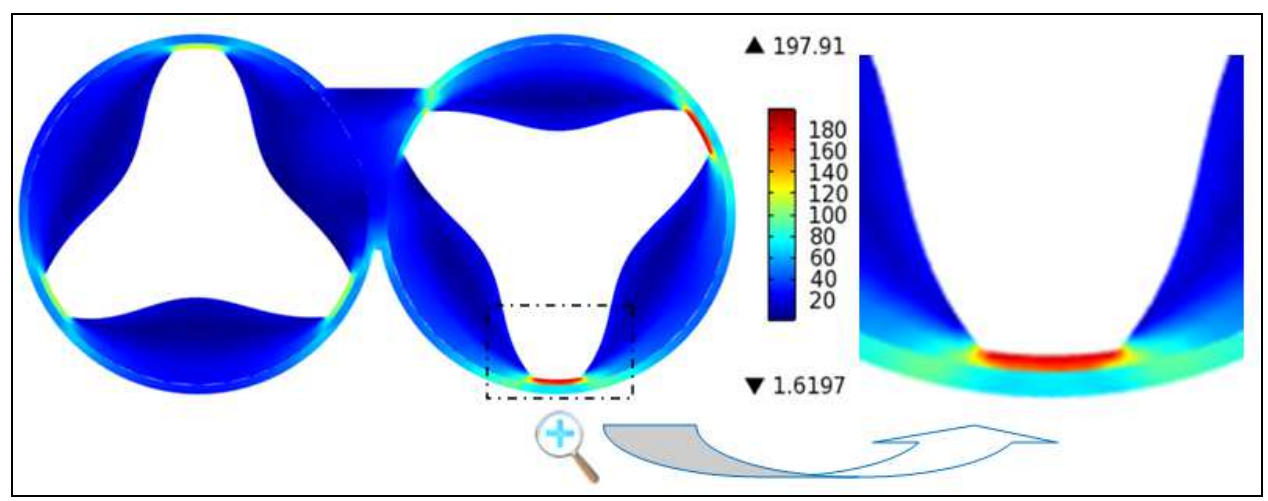

Fig. 12: Mapping of the shear rate distributions (1/s) for the PP/MWCNT $10 \mathrm{wt} . \%$ in the twin screw mixer and the twin screw mixer after 4 revolutions from the initial position. 
Fig. 12 show that the shear rate is relatively high throughout the intermeshing region where the mixing paddles interact in the twin screw mixer and are combined with elongational flow, especially near the tip of the screws and in the gap between the screws and the mixing chamber. When the mixing index and shear rate are considered in combination with the velocity vectors, it can be seen the flow is split and reoriented or folded in this region, which allows for the creation of elongational flow conditions.

\subsection{Experimental and numerical temperature field of the pure PP}

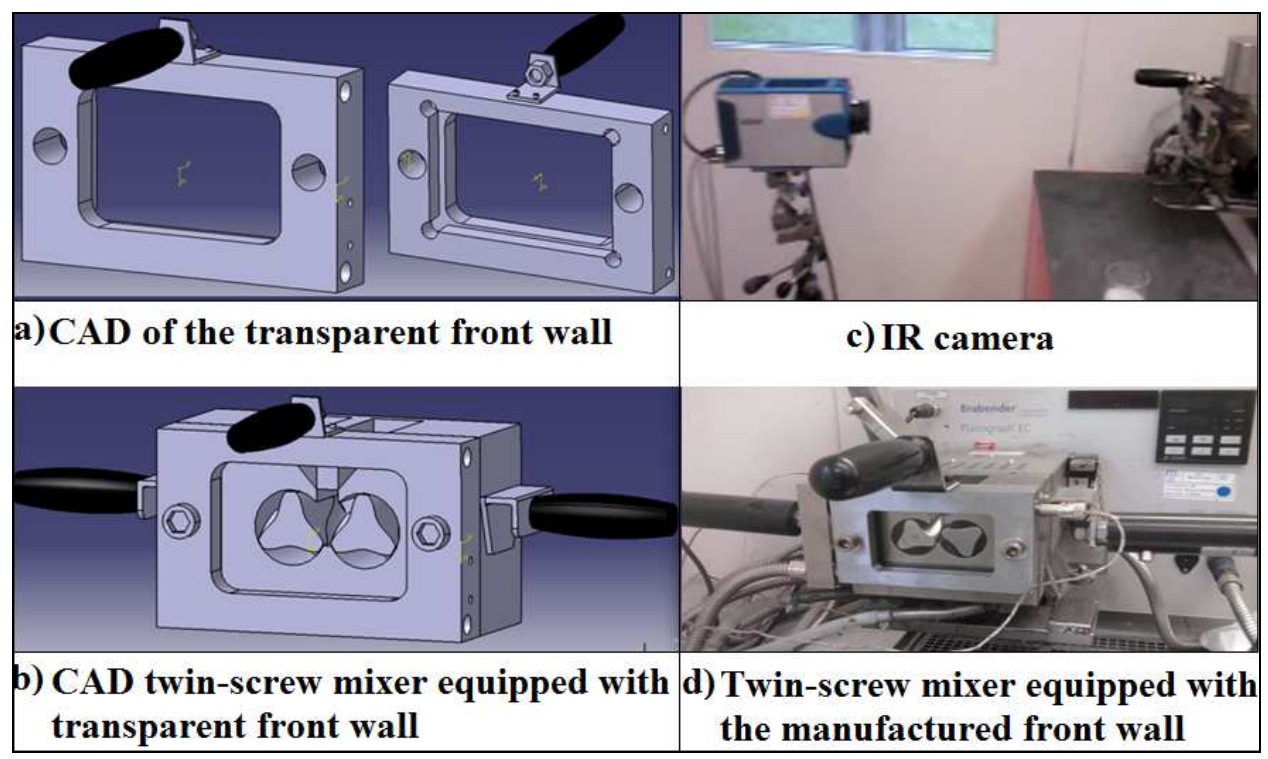

Fig. 13: Transparent front wall design for experimental temperature field visualization by infrared camera used on the twin-screw mixer: a) Transparent front wall CAD (CATIA) for different view sights b) infrared thermal camera c) twin screw mixer equipped with transparent wall

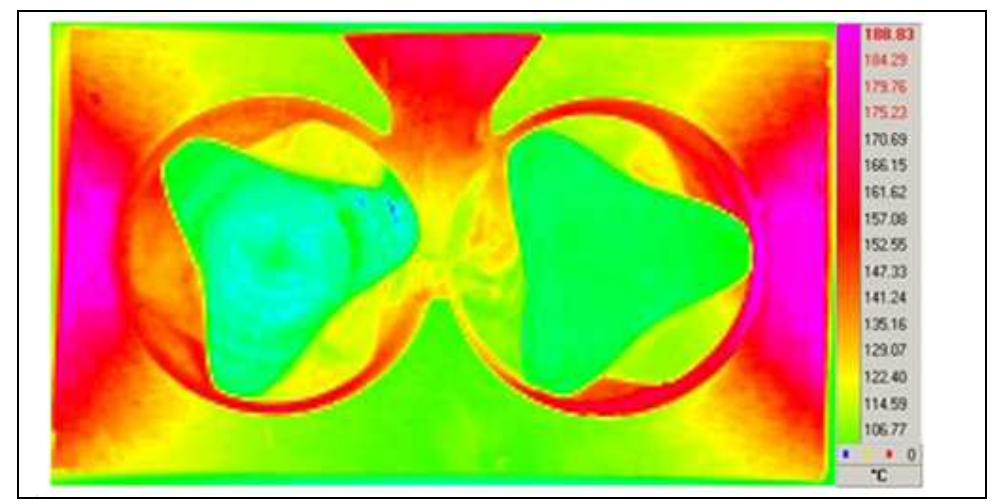

Fig. 14: Temperature fields $\left[{ }^{\circ} \mathrm{C}\right]$ within the mixer obtained by the infrared camera

The temperature field of the pure PP in the twin-screw mixer is shown in Fig. 14, the PP is introduced into the mixer after heated it at a temperature eq $200^{\circ} \mathrm{C}$ as shown in Fig. 12. b. After 90 s of mixing with rotation speed eq. $60 \mathrm{rpm}$, PP reaches the imposed temperature that guarantees optimal mixing conditions. 
Fig. 15: Temperature field (in K) at several time step for the PP/MWCNT $10 \mathrm{wt} . \%$ at $\mathrm{t}=0.5$ (half revolution)s $\mathrm{b}$ ) at $\mathrm{t}=3 \mathrm{~s}$ ( 3 revolutions $) ; \mathrm{c}$ ) at $\mathrm{t}=6 \mathrm{~s}$ (6 revolutions).

The temperature variations during mixing is shown in Fig. 15. At the beginning of the simulation, the $\mathrm{PP} / \mathrm{MWCNT}$ composite with temperature is globally equal to $150^{\circ} \mathrm{C}$ except on the frame and screws walls, where the temperature is imposed $\left(\mathrm{T}=200^{\circ} \mathrm{C}\right)$. During the simulation, the temperature in the cavity increases to a limit value equal to $200^{\circ} \mathrm{C}$, corresponding to the imposed mixing temperature on the frame and screws walls. This simulation clearly indicates that the mixing temperature is quickly reached, which guarantees optimal mixing conditions. The heat transfer influence, at the mixer inlet, is shown in these figures. This shows that a significant variation of the temperature in the middle of the cavity, where the temperature is practically equal to the PP melting temperature. 
Fig. 16: Experimental mixing torque versus time for the PP and PP/MWCNT feedstocks $(2,5,10 \%)$

The measured mixing torque versus time is shown in Fig. 16. One notices that the mixing torque increases with MWCNT content. As a general tendency, the mixing torque decreases with time to a limit torque. It can be related to the temperature of the PP/MWCNT feedstock increases until the imposed temperature, resulting in a decrease of the polypropylene shear viscosity. Very high values of the mixing torque are measured until 6 min when introducing feedstock into the mixer. It explains the fact that the beginning of effective mixing phase starts after $8 \mathrm{~min}$.

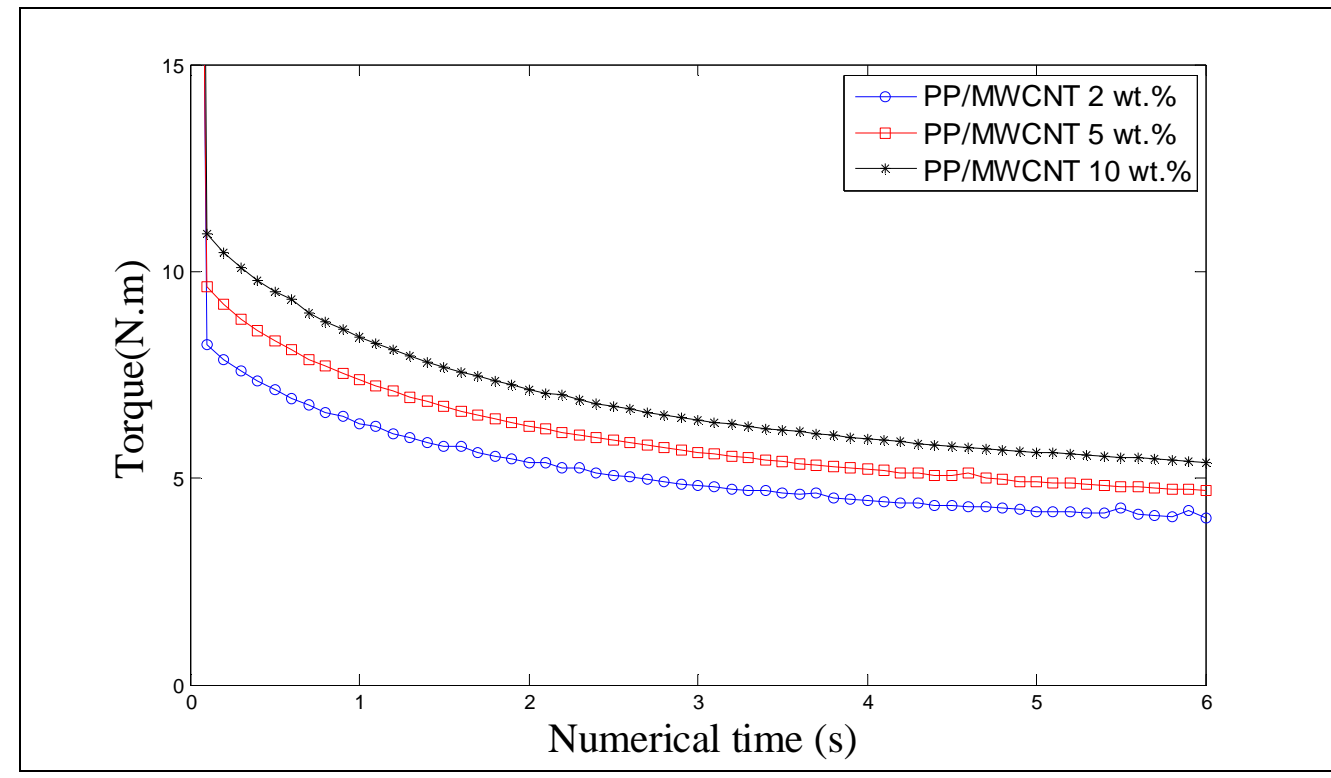

Fig. 17: Numerical mixing torque versus time for the PP/MWCNT feedstock $(2,5,10 \%)$

Fig. 17 shows that the torque increases with the MWCNT content. One can explain it due to the increase of the shear viscosity of the PP/MWCNT feedstock with the MWCNT content. The mixing torque decreases with time to a limit torque. It can be related to the temperature of the PP/MWCNT feedstock increases until the imposed temperature, resulting in a decrease of the polypropylene shear viscosity.

\section{CONCLUSION}


Recent analyses concerning physical modeling and numerical simulation of PP and PP/MWCNT viscous flow in the laminar regime, based on properly identified material behavior have been investigated using FEM.

The first part of the paper relates the experiments carried out for the determination of the rheological properties of PP and PP/MWCNT composite with various MWCNT contents estimated in the temperature range from 180 to $220^{\circ} \mathrm{C}$. The rheological properties have been determined in the range 10 à $10^{4}$ using capillary rheometry. The significant effects of the MWCNT content have been proved, as the increase of shear viscosity versus MWCNT volumic fraction associated to shear rate increase. These rheological characterizations have been used to set up and to build a constitutive model for the flow of PP/ MWCNT based on the extension of the well-known Carreau law coupled with a thermal factor. The resulting parameters have been identified for the neat PP and the PP/MWCNT composites. A transparent front wall has been designed for the twin screw mixer in order to measure the temperature field for the PP in the twin-screw mixer cavity using infrared camera with high quality thermal imaging.

The second part of the paper concerns the modelling of the PP and PP/MWCNT composite flow during the mixing stage in the twin screw mixer was performed using the finite element method in $\mathrm{Comsol}^{\odot}$ software. 2D numerical simulation results have been compared with experimental results concerning mixing torque, mixing index as well as temperature fields. The comparaison between experimental mixing torques and the ones obtained through the finite element simulations attests about the validity of the rheological flow model as well as the finite element results.

\section{Acknowledgements}

In this context, the Applied Mechanical Department (AMD) of the FEMTO-ST Institute began several years ago a new research and development Project called "NewPIM" which focuses on controlling conception and realization of micro-structured components.

\section{Nomenclature}

$$
\begin{array}{ll}
K & : \text { Extra stress tensor } \\
C_{p} & : \text { Specific heat } \\
D & : \text { Tensor rate deformation } \\
n & : \text { Power index } \\
b & : \text { Power index } \\
a & : \text { Yasuda index } \\
T & : \text { Temperature } \\
p & : \text { Pressure } \\
u & : \text { Fluid velocity } \\
f & : \text { External body force } \\
k & : \text { Thermal conductivity } \\
\text { Greek Symbols } & : \text { Density } \\
\rho & : \text { Stress tensor } \\
\sigma & : \text { Vorticity tensor } \\
\omega & : \text { Shear rate } \\
\dot{\gamma} &
\end{array}
$$


$\lambda \quad$ : Time characteristic

$\mu_{0}:$ Shear viscosity at zero shear rate

$\mu$ : Shear viscosity

Subscripts

ref : Reference

$M I \quad$ : Mixing index

\section{References}

[1] Donagh, Mc., "Mixers for Powder/Liquid Dispersion," The Chemical Engineer., 1987; pp29-32

[2] Akdogan. H, McHugh. T.H, "Twin screw extrusion of peach puree: Rheological properties and product characteristics," Journal of Food Processing and Preservation., 1999; 23: pp285-305.

[3] Thiébaud. F, Gelin. J-C, "Characterization of rheological behaviors of polypropylene/carbon nanotubes composites and modeling their flow in a twin-screw mixer," Composites Science and Technology., 2010; 70: pp647-656.

[4] Fasina. O.O, Hallman. C. H. M, and Clementsa. C, "Predicting Temperature-Dependence Viscosity of Vegetable Oils from Fatty Acid Composition," JAOCS., 2006; 83(10): 899-903

[5] Carreau. P, Kee. D. De, Chhabra. O, "Rheology of polymeric systems:principles and applications," Munich Hanser; 1997.

[6] Cross. M.M, "Rheology of non-Newtonian fluids: a new flow equation for pseudoplastic systems," J Colloid Sci., 1965; 20: pp417-37.

[7] Gelin. J-C, Barrière. T, Song. J, "Processing Defects and Resulting Mechanical Properties After Metal Injection Molding," J. Eng. Materials Technology-Trans. ASME., 2010; 132(1)

[8] Cheng. J. J, Manas-Zloczower. I, "Flow field characterization in a banbury mixer," International Polymer Processing., 1990; vol.3: pp178-183.

[9] Kelarakis. A, Yoon. K, Sics. I, Somani. R. H, Chen. X, Hsiao. B. S, "Shear-induced orientation and structure development in isotactic polypropylene melt containing modified carbon nanofibers," Journal of Macromolecular Science., 2006; 45: pp247-261.

[12] Djoudi. H, Gelin. J-C, Barrière. T, "Modeling and numerical simulation of metallic powders loaded polymers for PIM feedstocks." J. Steel Grips, Poland, in print (2012).

\section{List of figures}

Fig. 1: Twin screw mixer (velocity max. $150 \mathrm{rpm}$, max. temp $500^{\circ} \mathrm{C}$ ) Rheological characterization 
Fig. 2: Shear viscosity vs the shear rate measured at $200^{\circ} \mathrm{C}$ for the $\mathrm{PP}$ and $\mathrm{PP} / \mathrm{MWCNT}$

Fig. 3: Shear viscosity vs shear rate measured at 180,200 and $220^{\circ} \mathrm{C}$ for the $10 \% \mathrm{PP} / \mathrm{MWCNT}$ feedstock Fig. 4: Inverse problem scheme

Fig. 5: Comparison of different flow models for PP/MWCNT $10 \mathrm{wt} \%$

Fig. 6: Shear viscosity as a function of the shear rate measured at $200^{\circ} \mathrm{C}$ for the $\mathrm{PP}$ and PP/MWCNT feedstocks: experimental datas and Carreau law enriched temperature fitting curves.

Fig. 7. Description of the geometrical problem of the twin-screw mixing chamber in term of material frames and boundary conditions definition.

Fig. 8: Mesh definition related to twin screws mixer discretization (30876 DOF)

Fig. 9: Interactions algorithm between "material flow", "heat transfer" and "moving mesh module".

Fig. 10: Velocity vectors indicating direction of the PP/MWCNT $10 \mathrm{wt}$ \% flow and velocity magnitude $(\mathrm{m} / \mathrm{s})$ of the twin screw mixer after 3 revolutions

Fig. 11: Mapping of the mixing index $\left(\lambda_{M I}\right)$ for PP/MWCNT $10 \mathrm{wt} \%$ in the twin screw mixer after 3 revolutions from the initial position (a value eq.0 indicates pure rotation, a value eq. 0.5 indicates shear flow and a value of 1 indicates pure elongation).

Fig. 12: Mapping of the shear rate distributions (1/s) for the PP/MWCNT $10 \mathrm{wt} \%$ in the twin screw mixer and the twin screw mixer after 4 revolutions from the initial position.

Fig. 13: Transparent front wall design for experimental temperature field visualization by infrared camera used on the twin-screw mixer: a) Transparent front wall CAD (CATIA) for different view sights b) infrared thermal camera c) twin screw mixer equipped with transparent wall

Fig. 14: Temperature fields $\left[{ }^{\circ} \mathrm{C}\right]$ obtained by the infrared camera for neat PP: a) experimental temperature field before the introduction of the material; b) Numerical temperature field before the introduction of the material

Fig. 15: Temperature field (in K) at several time step for the PP/MWCNT 10 wt.\% at $\mathrm{t}=0.5$ (half revolution)s $\mathrm{b}$ ) at $\mathrm{t}=3 \mathrm{~s}$ ( 3 revolutions); $\mathrm{c}$ ) at $\mathrm{t}=6 \mathrm{~s}$ (6 revolutions).

Fig. 16: Experimental mixing torque versus time for the PP and PP/MWCNT feedstocks (2, 5, 10\%)

Fig. 17: Numerical mixing torque versus time for the PP/MWCNT feedstock $(2,5,10 \%)$

\section{List of tables}

Table 1: Rheological models parameters for the PP/MWCNT $10 \mathrm{wt} . \%$ 


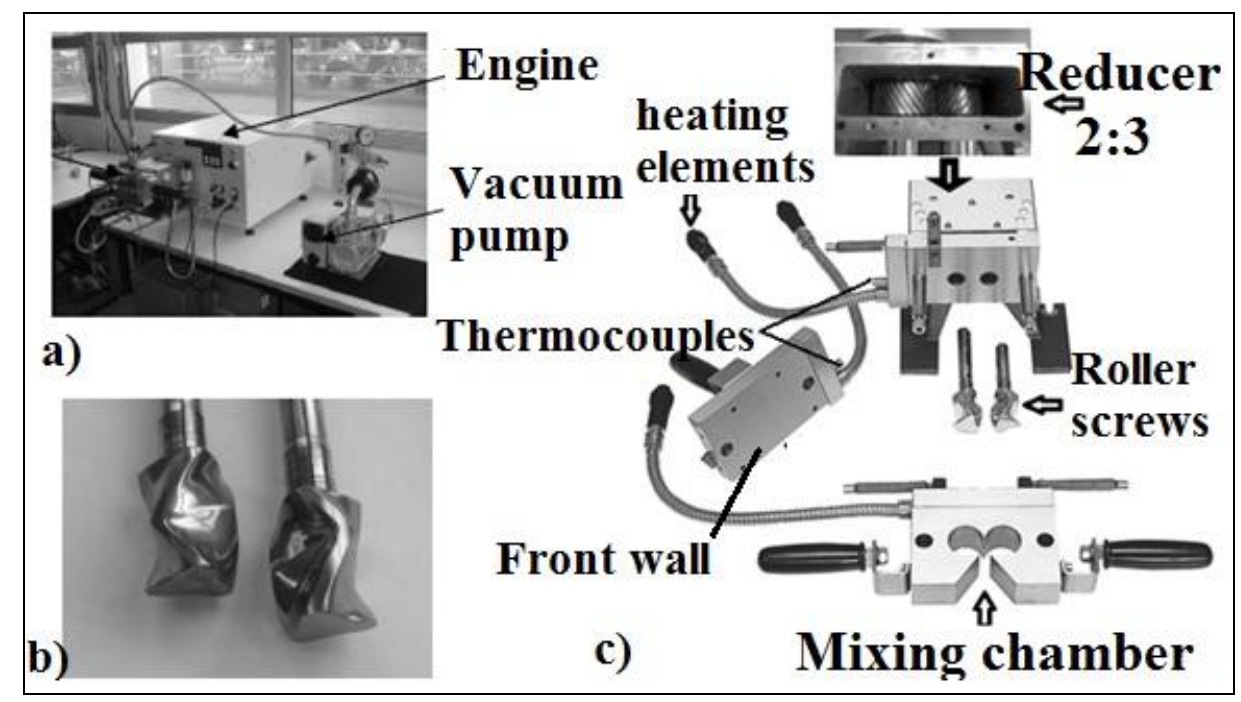

Fig. 1: Twin screw mixer (velocity max. $150 \mathrm{rpm}$, max. temp $500^{\circ} \mathrm{C}$ ) 


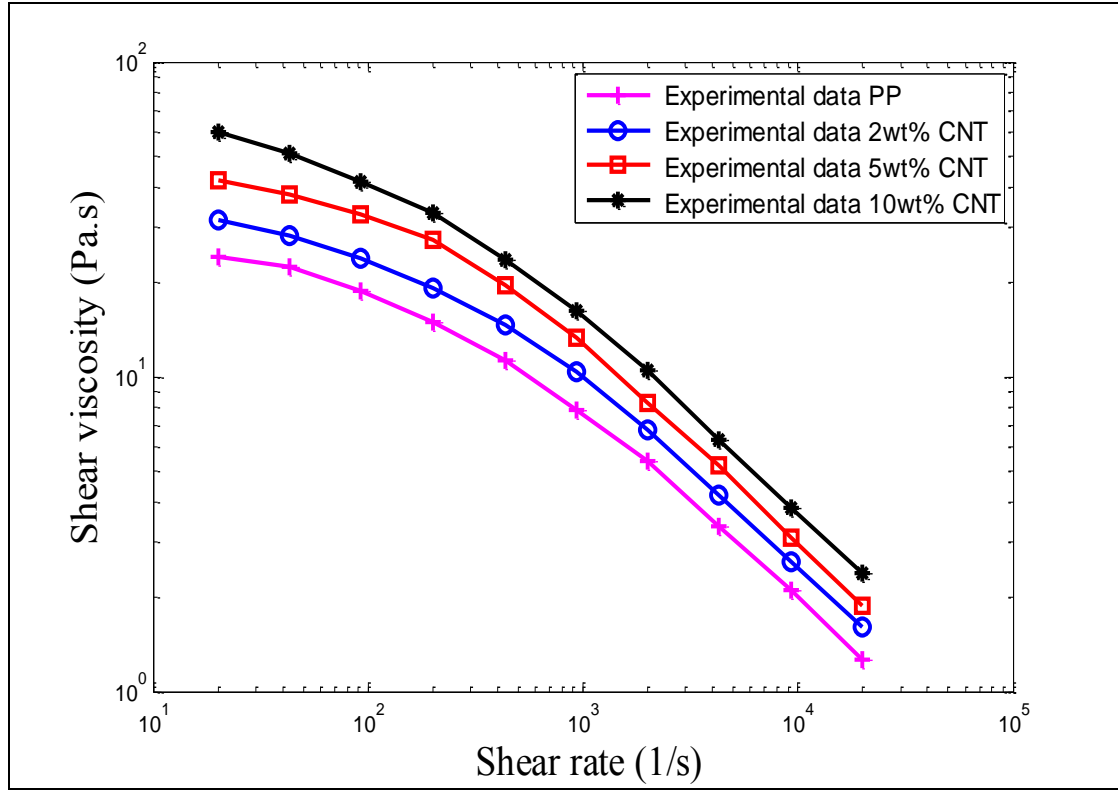

Fig. 2: Shear viscosity vs the shear rate measured at $200^{\circ} \mathrm{C}$ for the PP and PP/MWCNT 


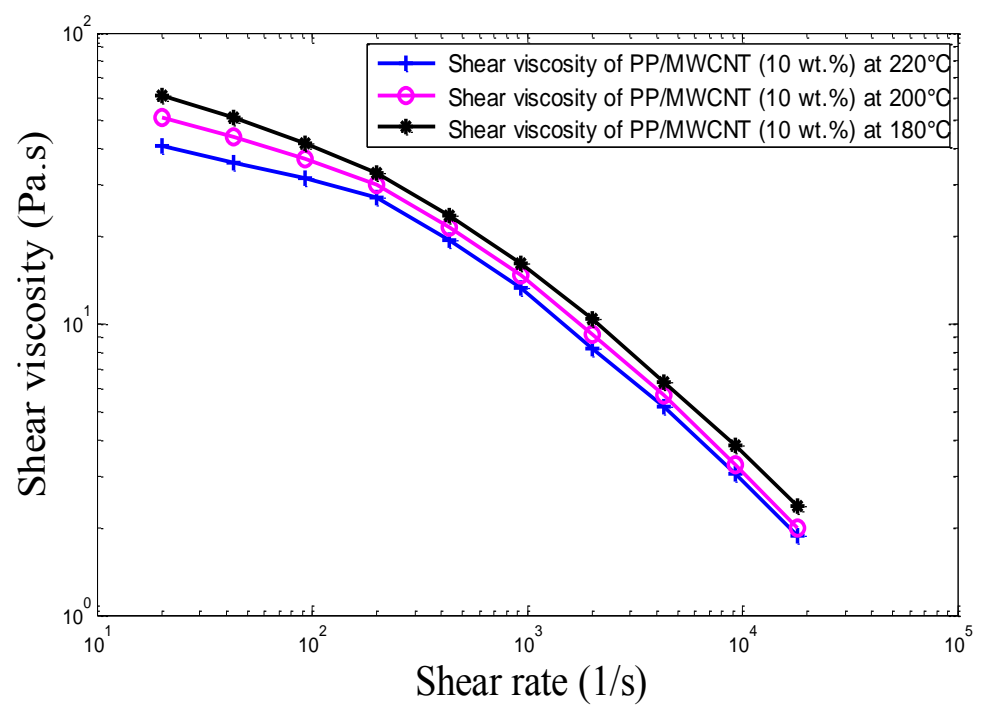

Fig. 3: Shear viscosity vs shear rate measured at 180,200 and $220^{\circ} \mathrm{C}$ for the $10 \% \mathrm{PP} / \mathrm{MWCNT}$ feedstock 

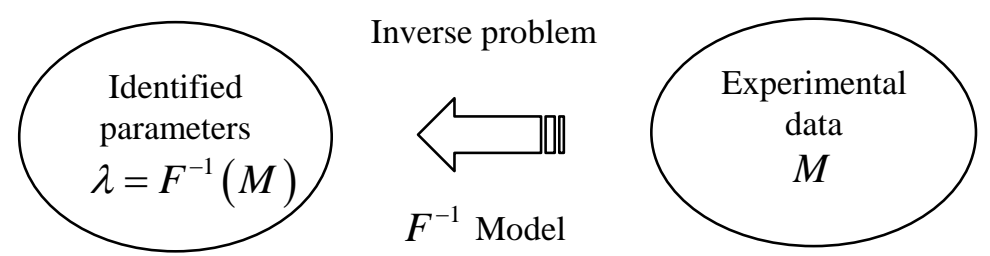

Fig. 4: Inverse problem scheme 


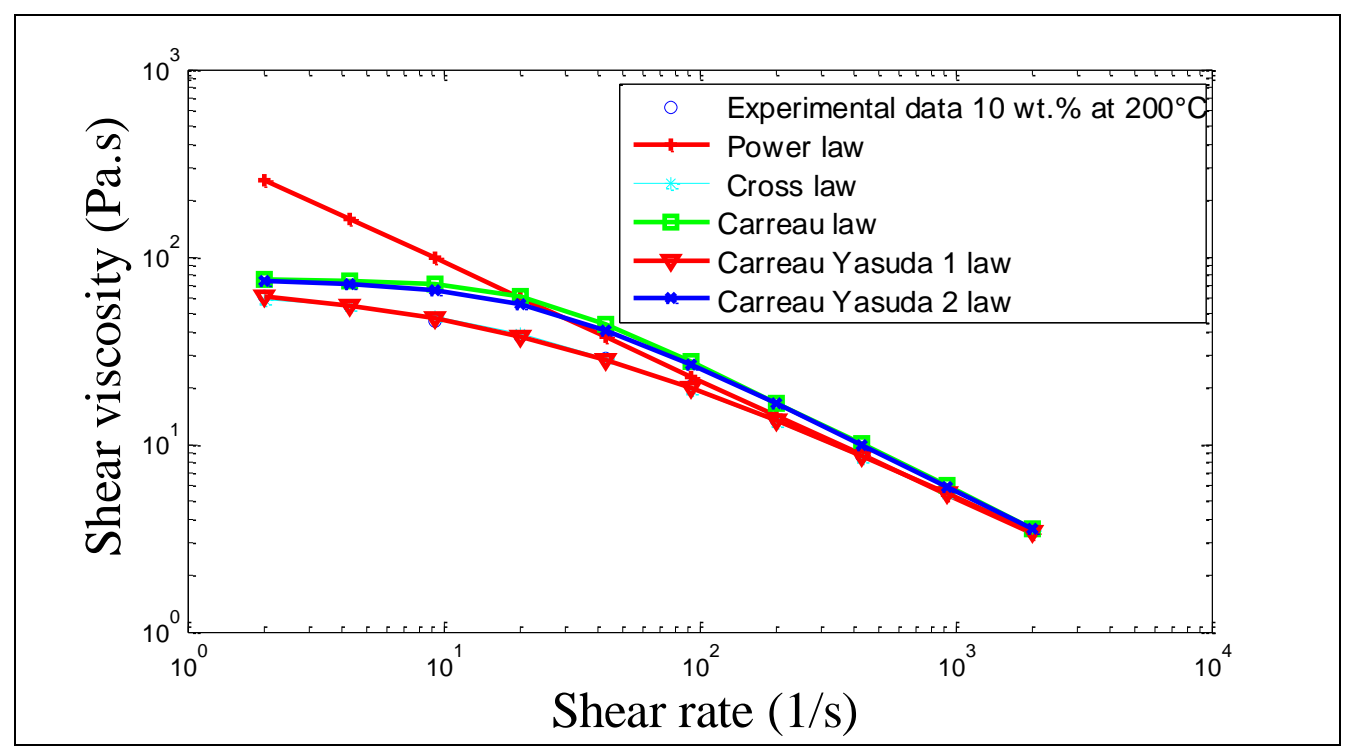

Fig. 5: Comparison of different flow models for PP/MWCNT 10 wt.\% 


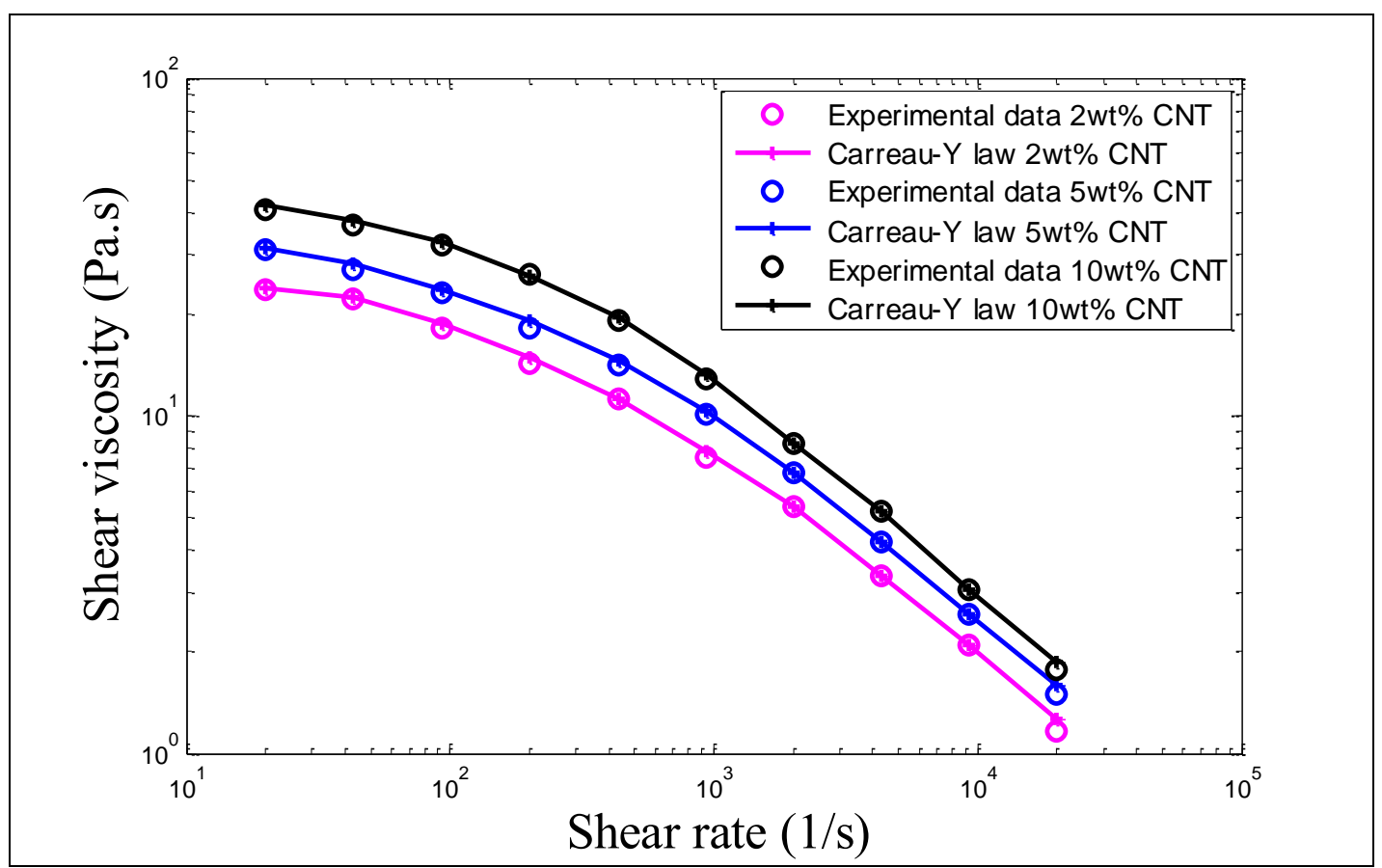

Fig. 6: Shear viscosity as a function of the shear rate measured at $200^{\circ} \mathrm{C}$ for the $\mathrm{PP}$ and $\mathrm{PP} / \mathrm{MWCNT}$ feedstocks: experimental datas and Carreau law enriched temperature fitting curves. 


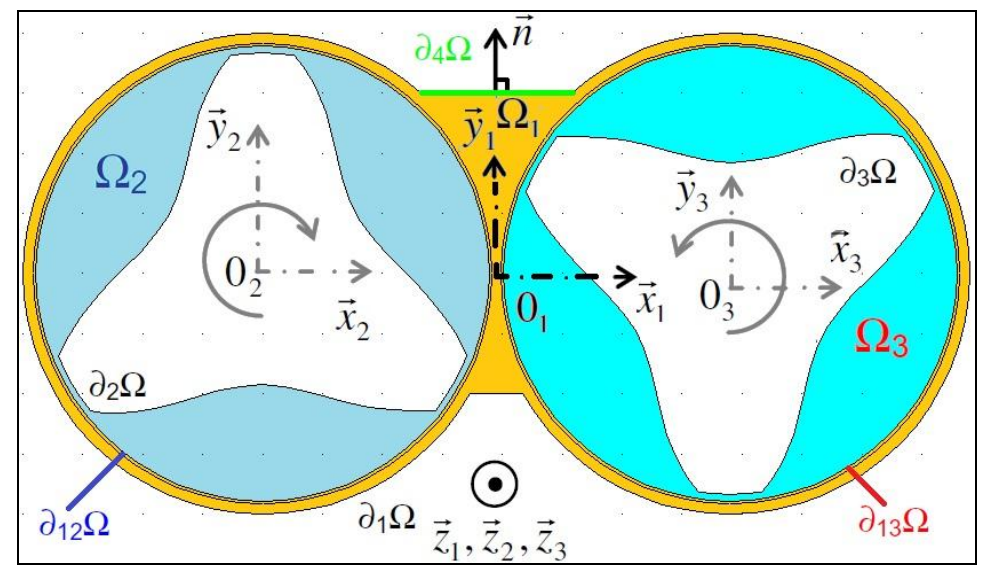

Fig. 7. Description of the geometrical problem of the twin-screw mixing chamber in term of material frames and boundary conditions definition. 


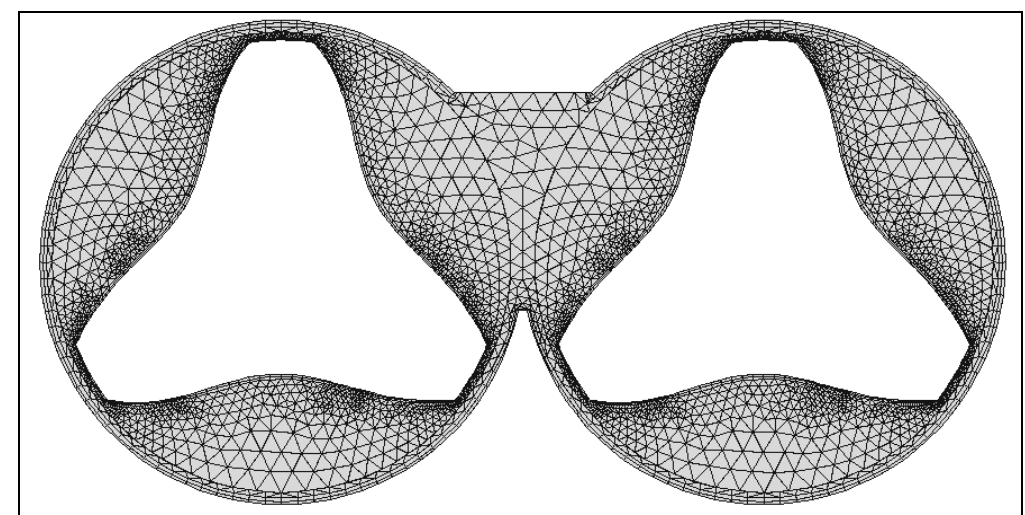

Fig. 8: Mesh definition related to twin screws mixer discretization (30876 DOF) 


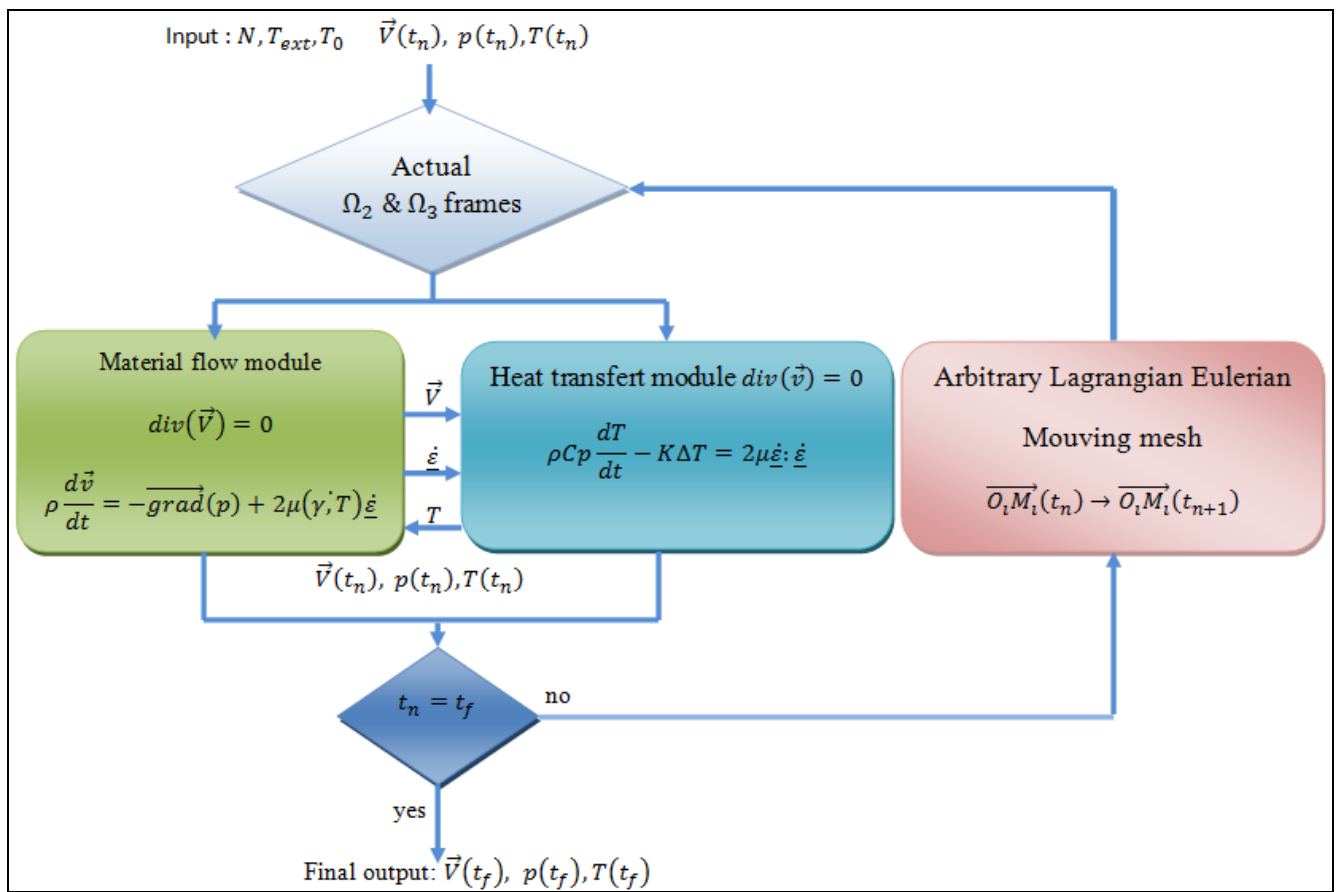

Fig. 9: Interactions algorithm between "material flow", "heat transfer" and "moving mesh module". 


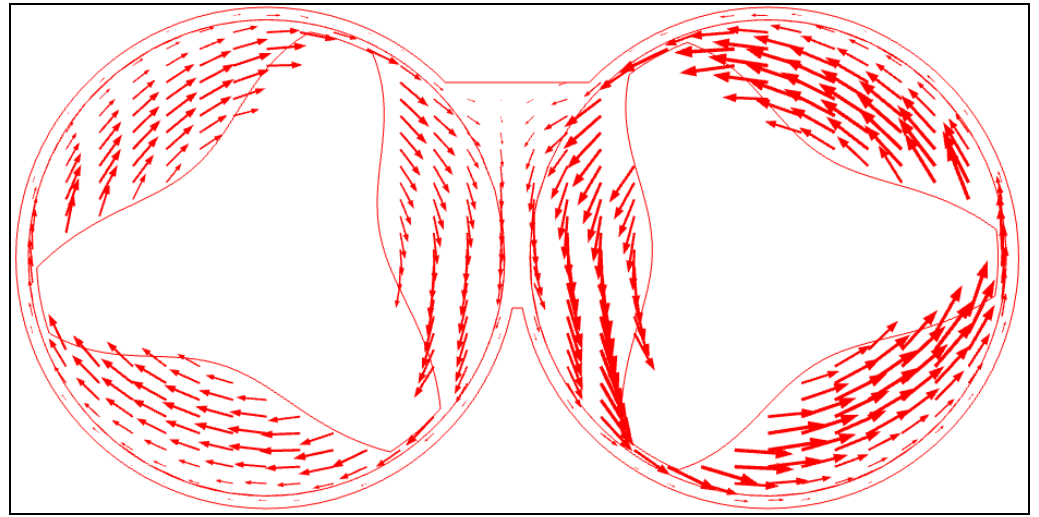

Fig. 10: Velocity vectors indicating direction of the PP/MWCNT $10 \mathrm{wt} . \%$ flow and velocity magnitude $(\mathrm{m} / \mathrm{s})$ of the twin screw mixer after 3 revolutions 


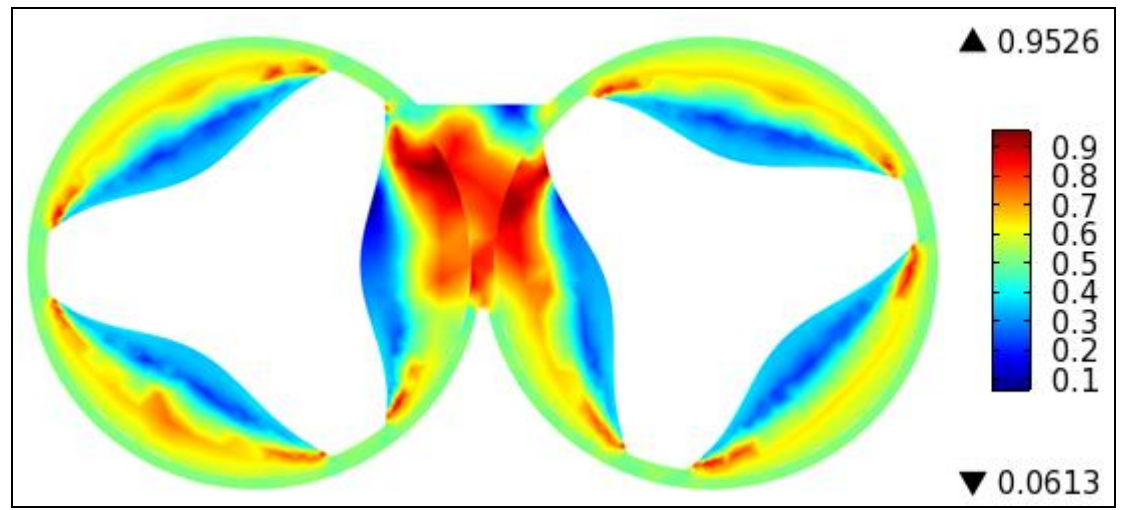

Fig. 11: Mapping of the mixing index $\left(\lambda_{M I}\right)$ for PP/MWCNT $10 \mathrm{wt} \%$ in the twin screw mixer after 3 revolutions from the initial position (a value eq.0 indicates pure rotation, a value eq. 0.5 indicates shear flow and a value of 1 indicates pure elongation). 


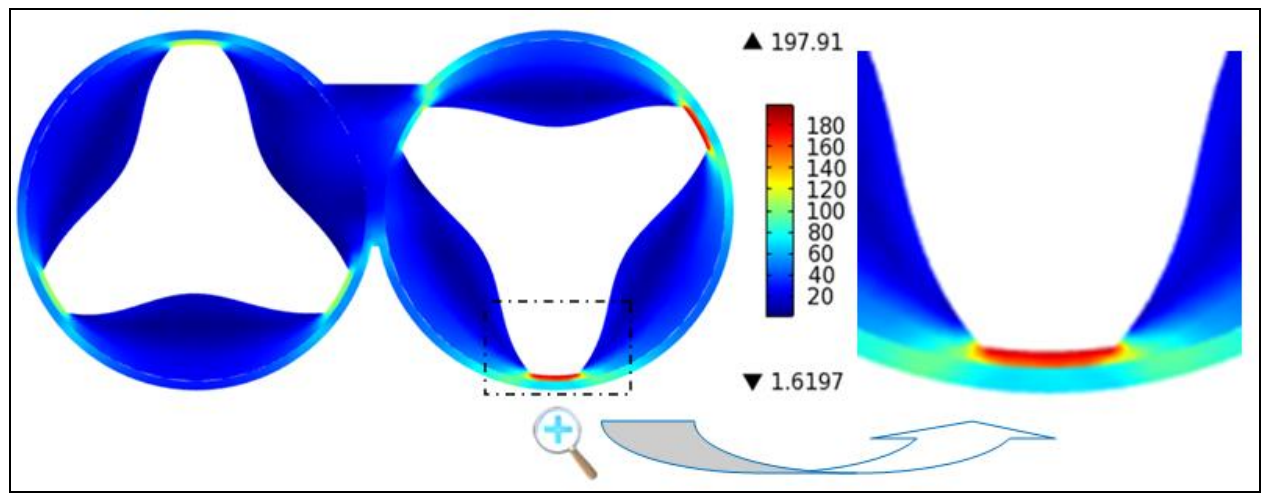

Fig. 12: Mapping of the shear rate distributions (1/s) for the PP/MWCNT $10 \mathrm{wt} \%$ in the twin screw mixer and the twin screw mixer after 4 revolutions from the initial position. 


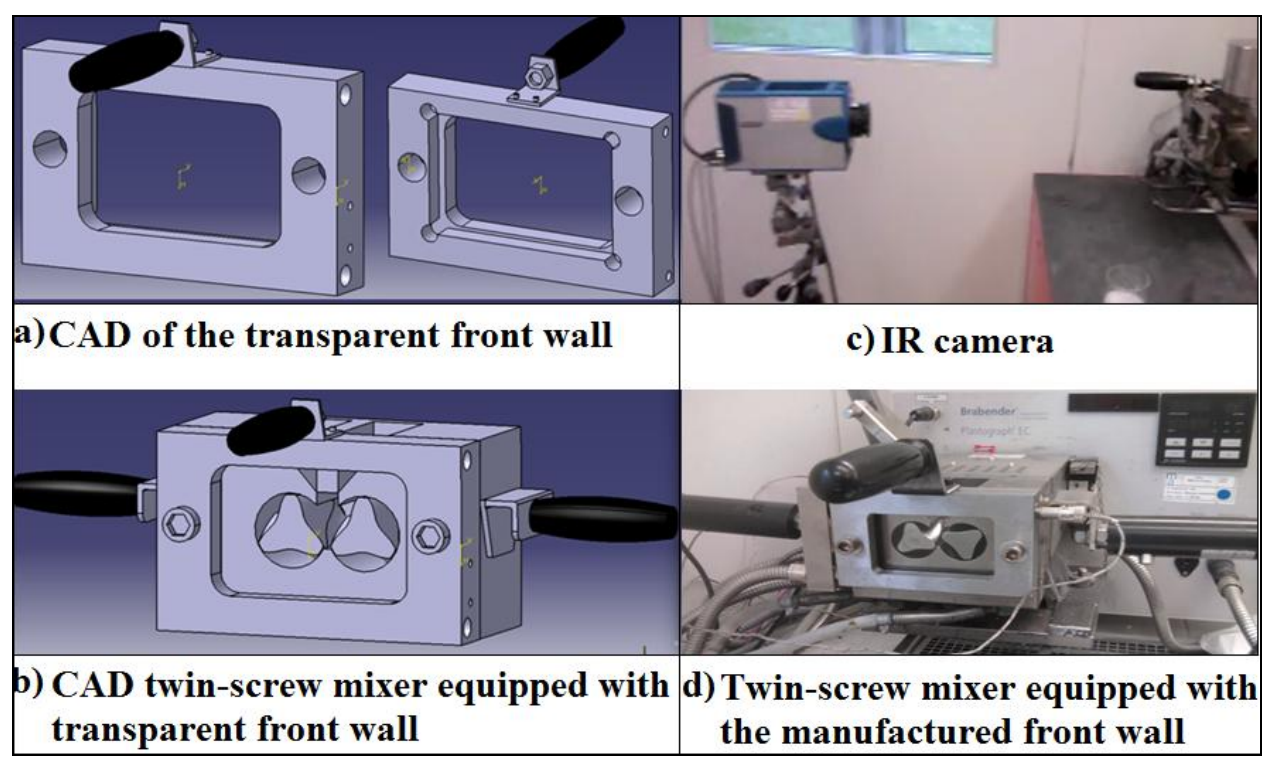

Fig. 13: Transparent front wall design for experimental temperature field visualization by infrared camera used on the twin-screw mixer: a) Transparent front wall CAD (CATIA) for different view sights b) infrared thermal camera c) twin screw mixer equipped with transparent wall 


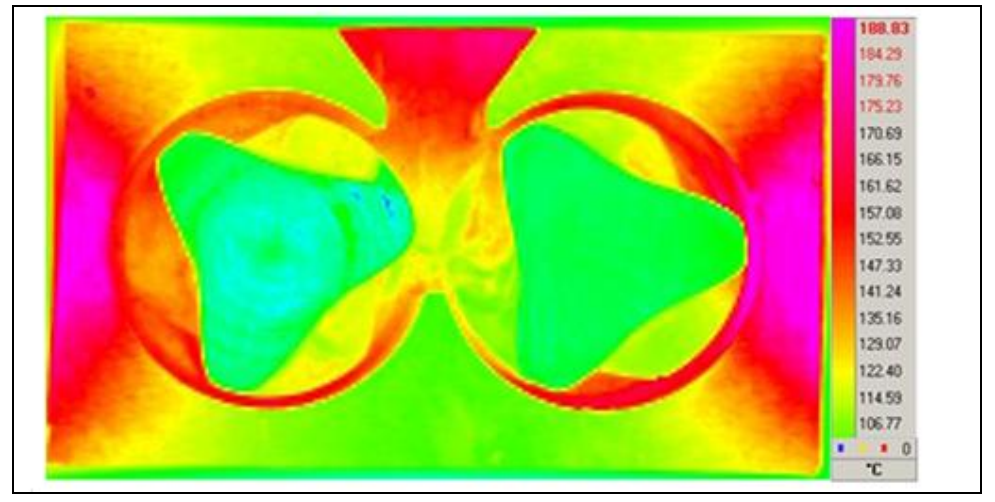

Fig. 14: Temperature fields $\left[{ }^{\circ} \mathrm{C}\right]$ within the mixer obtained by the infrared camera

The temperature field of the pure PP in the twin-screw mixer is shown in Fig. 14, the PP is introduced into the mixer after heated it at a temperature eq $200^{\circ} \mathrm{C}$ as shown in Fig. 12. b. After 90 s of mixing with rotation speed eq. $60 \mathrm{rpm}$, PP reaches the imposed temperature that guarantees optimal mixing conditions. 


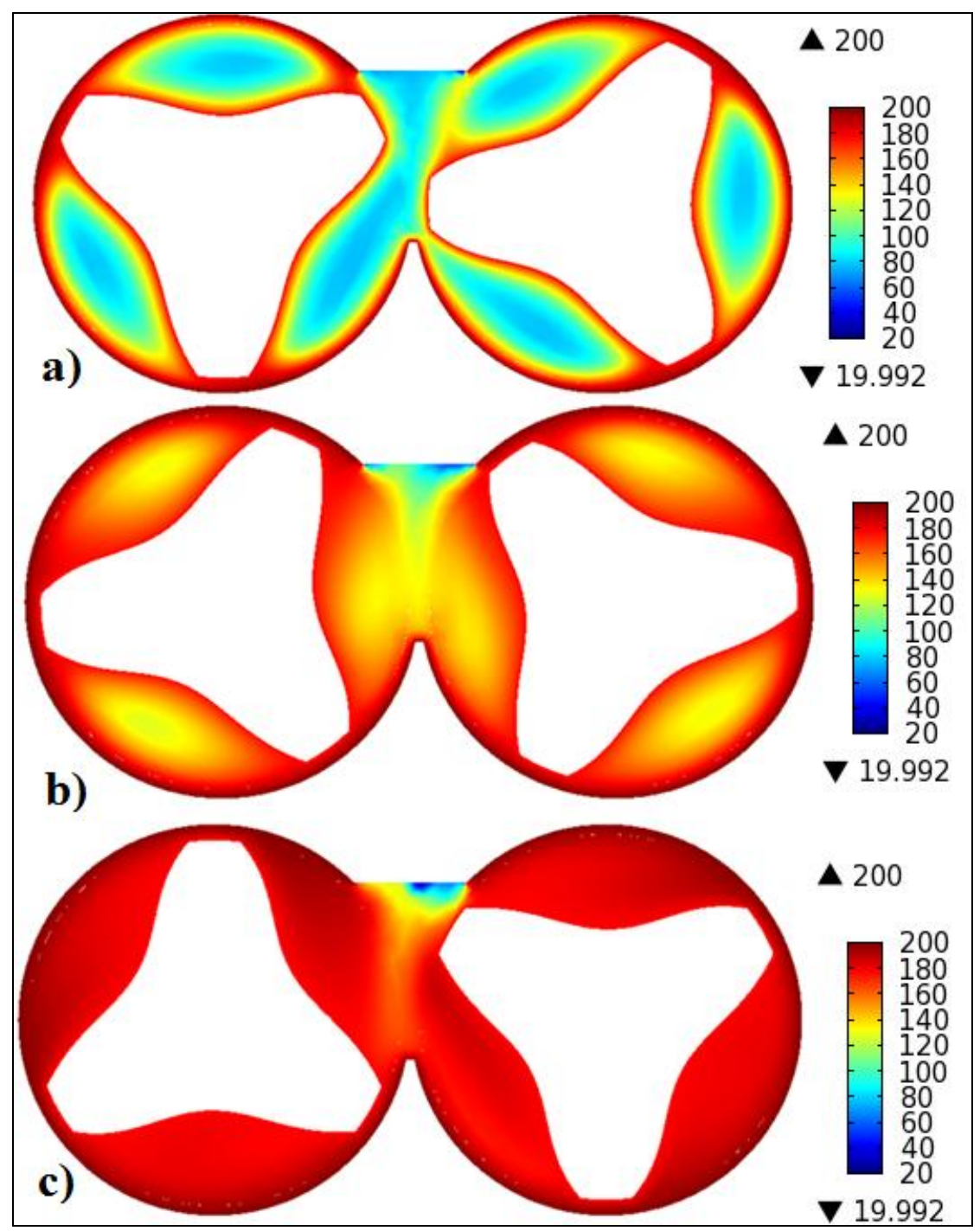

Fig. 15: Temperature field (in K) at several time step for the PP/MWCNT $10 \mathrm{wt} . \%$ at $\mathrm{t}=0.5$ (half revolution)s $\mathrm{b}$ ) at $\mathrm{t}=3 \mathrm{~s}$ ( 3 revolutions $) ; \mathrm{c}$ ) at $\mathrm{t}=6 \mathrm{~s}$ ( 6 revolutions). 


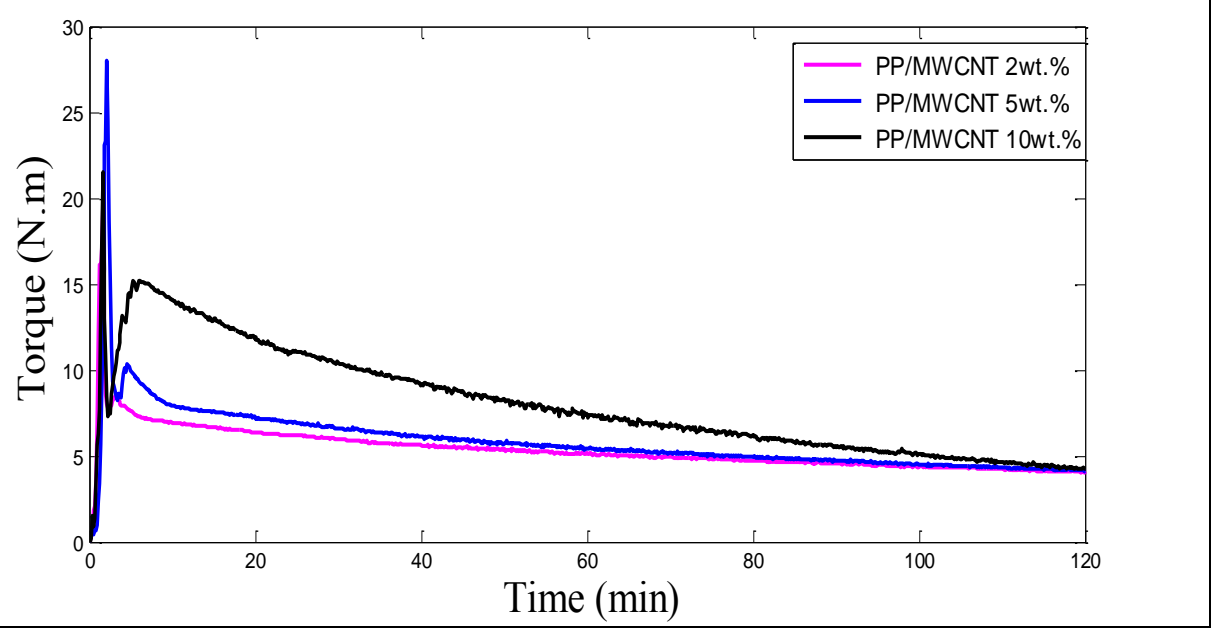

Fig. 16: Experimental mixing torque versus time for the PP and PP/MWCNT feedstocks $(2,5,10 \%)$ 


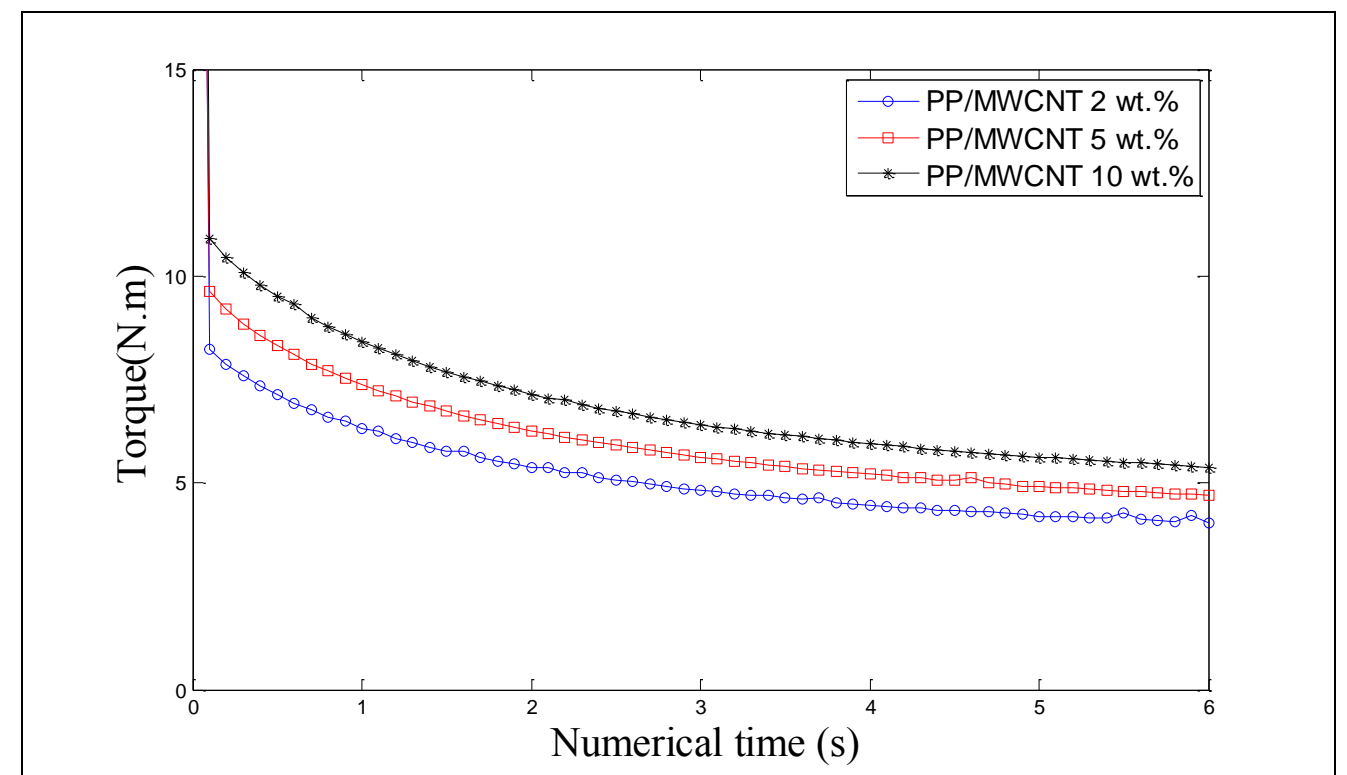

Fig. 17: Numerical mixing torque versus time for the PP/MWCNT feedstock $(2,5,10 \%)$ 


\section{Elaboration and ch}

Table 1: Rheological models parameters for the PP/MWCNT 10 wt.\%

\begin{tabular}{|l|c|c|c|c|c|c|}
\hline & $T_{r e f}{ }^{\circ} \mathrm{C}$ & $\mu_{0}$ & $\lambda(\mathrm{s})$ & $n$ & $a$ & $b$ \\
\hline Carreau-Y & 200 & 80 & 0.17 & 0.38 & 0.16 & 0.015 \\
\hline
\end{tabular}


Table 2: Physical and thermal parameters for the PP and PP/MWCNT 10 wt.\% Feedstock.

\begin{tabular}{|c|c|c|c|}
\hline & $\rho\left(\mathrm{cm}^{3} / \mathrm{g}\right)$ & $C_{p}\left(\mathrm{~J}^{\mathrm{kg}} \mathrm{kg}^{-1}\right)$ & $k\left(\mathrm{Wm}^{-1} \mathrm{~kg}^{-1}\right)$ \\
\hline PP & 0.904 & 1800 & 0.2 \\
\hline PP/MWCNT & 0.816 & 2100 & 0.35 \\
\hline
\end{tabular}

